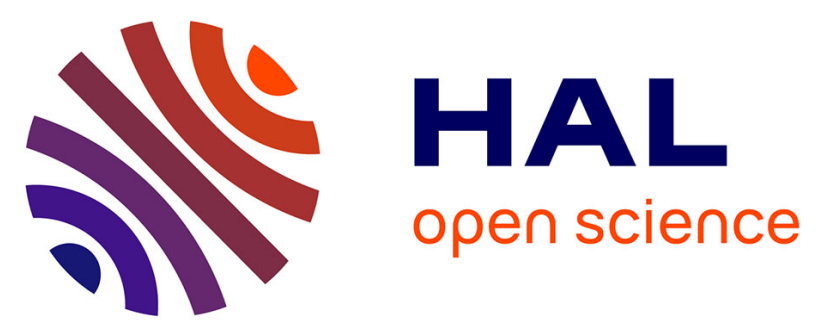

\title{
Rosiglitazone increases cell surface GLUT4 levels in 3T3-L1 adipocytes through an enhancement of endosomal recycling
}

Laurène Martinez, Marion Berenguer, M. Christine Bruce, Yannick Le Marchand-Brustel, Roland Govers

\section{To cite this version:}

Laurène Martinez, Marion Berenguer, M. Christine Bruce, Yannick Le Marchand-Brustel, Roland Govers. Rosiglitazone increases cell surface GLUT4 levels in 3T3-L1 adipocytes through an enhancement of endosomal recycling. Biochemical Pharmacology, 2010, 79 (9), pp.1300. 10.1016/j.bcp.2009.12.013 . hal-00573916

\section{HAL Id: hal-00573916 https://hal.science/hal-00573916}

Submitted on 5 Mar 2011

HAL is a multi-disciplinary open access archive for the deposit and dissemination of scientific research documents, whether they are published or not. The documents may come from teaching and research institutions in France or abroad, or from public or private research centers.
L'archive ouverte pluridisciplinaire $\mathbf{H A L}$, est destinée au dépôt et à la diffusion de documents scientifiques de niveau recherche, publiés ou non, émanant des établissements d'enseignement et de recherche français ou étrangers, des laboratoires publics ou privés. 


\section{Accepted Manuscript}

Title: Rosiglitazone increases cell surface GLUT4 levels in 3T3-L1 adipocytes through an enhancement of endosomal recycling

Authors: Laurène Martinez, Marion Berenguer, M. Christine Bruce, Yannick Le Marchand-Brustel, Roland Govers

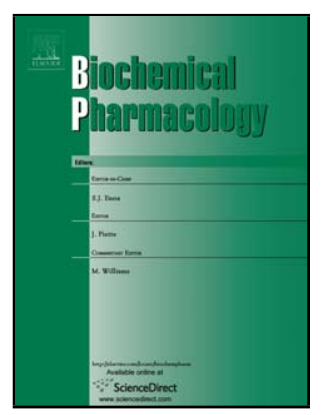

PII: S0006-2952(09)01071-5

DOI: doi:10.1016/j.bcp.2009.12.013

Reference: BCP 10410

To appear in: $\quad B C P$

Received date: $\quad 23-10-2009$

Revised date: 6-12-2009

Accepted date: $\quad$ 10-12-2009

Please cite this article as: Martinez L, Rosiglitazone increases cell surface GLUT4 levels in 3T3-L1 adipocytes through an enhancement of endosomal recycling, Biochemical Pharmacology (2008), doi:10.1016/j.bcp.2009.12.013

This is a PDF file of an unedited manuscript that has been accepted for publication. As a service to our customers we are providing this early version of the manuscript. The manuscript will undergo copyediting, typesetting, and review of the resulting proof before it is published in its final form. Please note that during the production process errors may be discovered which could affect the content, and all legal disclaimers that apply to the journal pertain. 
Rosiglitazone increases cell surface GLUT4 levels in 3T3-L1 adipocytes through an enhancement of endosomal recycling

Laurène Martinez, Marion Berenguer, M. Christine Bruce, Yannick Le Marchand-Brustel, Roland Govers

Inserm U895, Mediterranean Research Center for Molecular Medicine (C3M), Avenir Team 9, Nice, F-06204, France, and University of Nice-Sophia-Antipolis, Faculty of Medicine, Signaling and pathologies (IFR50), Nice, F-06107, France

E-mail addresses:

laurene.martinez@unice.fr (L. Martinez);

marion.berenguer@unice.fr (M. Berenguer);

bruce@unice.fr (M.C. Bruce);

lemarcha@unice.fr (Y. Le Marchand-Brustel);

govers@unice.fr (R. Govers)

\title{
Corresponding author
}

\author{
Roland Govers \\ Avenir Team 9 \\ Inserm U895, C3M \\ Bâtiment Archimed \\ 151 route de Ginestière \\ BP 23194 \\ 06204 Nice Cedex 3 \\ phone +33-4-89064227 \\ fax +33-4-89064221 \\ email govers@unice.fr
}




\begin{abstract}
Insulin induces a translocation of the glucose transporter GLUT4 from intracellular storage compartments towards the cell surface in adipocytes and skeletal muscle cells, allowing the cells to take up glucose. In type 2 diabetes-associated insulin resistance, the efficiency of this process is reduced. The thiazolidinediones, widely prescribed as anti-diabetic therapy, are generally regarded as insulin-sensitizers. The aim of this study was to evaluate the effect of the thiazolidinedione rosiglitazone (BRL 49653) on GLUT4 in adipocytes. When applied during differentiation, rosiglitazone dose dependently augmented GLUT4 expression along with the formation of lipid droplets. Intriguingly, its presence during differentiation led to increases in both cell surface GLUT4 levels and insulin-sensitivity of GLUT4 translocation in mature adipocytes. Treatment of fully differentiated adipocytes with rosiglitazone also led to increases in GLUT4 at the plasma membrane. Rosiglitazone similarly affected cell surface levels of the endosomal transferrin receptor, but did not alter the GLUT4 internalization rate. The augmentation in cell surface GLUT4 levels was maintained in adipocytes that were rendered insulin resistant in vitro by a 24 hour insulin treatment and moreover in these cells rosiglitazone also fully restored insulin-induced GLUT4 translocation. We conclude that in adipocytes, rosiglitazone increases cell surface GLUT4 levels by increasing its endosomal recycling and restores insulin-induced GLUT4 translocation in insulin resistance. These results implicate novel modes of action on GLUT4 that are all likely to contribute to the insulin-sensitizing effect of rosiglitazone in type 2 diabetes.
\end{abstract}

\title{
Keywords
}

GLUT4, thiazolidinedione, rosiglitazone, diabetes type 2, insulin resistance, adipocyte 


\section{Introduction}

Since their initial availability 15 years ago, the thiazolidinediones (TZDs) have been widely prescribed as medication for type 2 diabetes (T2D) [1, 2]. In addition to a direct effect on insulin-regulated glucose homeostasis in vivo (i.e. reducing insulin resistance), TZD administration has been associated with an amelioration of plasma lipid profiles, fat distribution, blood pressure, inflammation, endothelial dysfunction, and atherosclerosis $[2,3]$.

TZDs are agonists for the transcription factor peroxisome proliferator-activated receptorgamma (PPAR $\gamma)$. This nuclear receptor regulates the synthesis of proteins involved in glucose and lipid homeostasis and is mostly present in adipose tissue [4]. PPAR $\gamma$, together with $\mathrm{C} / \mathrm{EBP}$, is regarded as the master regulator of fat cell differentiation. TZDs increase efficacy and kinetics of adipocyte differentiation [5,6] and suppress TNF $\alpha$-mediated inhibition of adipocyte differentiation [7, 8]. In vivo, PPAR $\gamma$ ablation is accompanied by an absence of all types of adipose tissue [9], while in vitro its inactivation results in a downregulation of the expression of genes that confer the characteristics of mature adipocytes [10]. While the primary (adipogenic) action of TZDs occurs in adipose tissue, their insulin-sensitizing effects mostly take place in skeletal muscle [11]. While these two actions may seem relatively unrelated, the effects in muscle could be indirect and possibly due to a reversal of fatty acid accumulation in muscle resulting from an increased fatty acid metabolism in adipose tissue [12]. In addition, TZD-mediated PPAR $\gamma$ activation alters the secretion of adipokines that are involved in the regulation of insulin sensitivity and glucose metabolism (e.g. TNF $\alpha$ and leptin), leading to improvements in insulin action in multiple insulin-sensitive tissues $[2,6]$. In any case, it is unlikely that the low PPAR $\gamma$ levels in muscle and liver (10-30 times lower than in adipose tissue) are directly responsible for some of the insulin-sensitizing effects as 
TZDs do not display insulin-sensitizing effects in mice lacking adipose tissue [13] and TZDs hardly activate PPAR $\gamma$-responsive genes in muscle and liver [14].

In insulin resistance in vivo, TZD troglitazone restores decreased GLUT4 expression levels in adipose tissue of the T2D animal model OLETF (Otsuka Long-Evans Tokushima Fatty rat) [15]. An increase in GLUT4 expression in adipocytes was also described for rosiglitazone in $d b / d b$ mice [16]. However, suppression of insulin resistance in the absence of alterations in GLUT4 expression has been reported for englitazone in adipocytes of high fat diet rats [17] and for englitazone and pioglitazone in muscle of glucocorticoid-treated rats [18]. In insulin resistance in vitro, rosiglitazone has been suggested to rescue impaired glucose transport by restoring baseline levels of reactive oxygen species (ROS) [19]. However, it is not known whether and how GLUT4 is involved in this rescue. In any case, there is no report yet that describes the effects of rosiglitazone on GLUT4 in vitro.

Here, we investigated the effects of rosiglitazone on GLUT4 in (pre)adipocytes, notably its expression and cell surface levels. In addition, we examined whether the effect on cell surface amounts was specific for GLUT4 and maintained under conditions of insulin resistance. 


\section{Materials and methods}

\subsection{Materials}

3T3-L1 murine preadipocytes were obtained from the American Type Culture Collection ATCC/LGC Standards (Teddington, UK) and Plat-E cells, used for the generation of retrovirus, were kindly provided by Dr Toshio Kitamura (University of Tokyo, Tokyo, Japan). Sera were from PAA (Pasching, Austria), media and HEPES from Invitrogen (Carlsbad, CA, USA), and insulin from Lilly (Suresnes, France). Monoclonal anti-HA antibody was obtained from Covance (Emeryville, CA, USA), fluorescent antibodies and TOPRO3 from Molecular Probes/Invitrogen (Carlsbad, CA, USA), anti-transferrin receptor from Zymed/Invitrogen (Carlsbad, CA, USA), and antibodies against GLUT4 and insulin receptor and HRPconjugated secondary antibodies from Santa Cruz Biotechnology (Santa Cruz, CA, USA). Antibody against syntaxin-13 was generously provided by Dr Rytis Prekeris (University of Colorado, Denver, CO, USA). Anti-tubulin antibody, mouse IgG antibody and all other chemicals were purchased from Sigma-Aldrich (St. Louis, MO, USA). Rosiglitazone, troglitazone, and pioglitazone were from Alexis/Axxora (Lausen, Switzerland). Unless indicated otherwise, rosiglitazone was used at a concentration of $10 \mu \mathrm{M}$. pBABE vector was kindly provided by Dr Hartmut Land (University of Rochester, Rochester, NY, USA).

\subsection{Molecular biology}

The cDNA encoding HA-GLUT4 (GLUT4 with an HA epitope tag in its first luminal domain) inserted in pBABE-puro vector is described elsewhere [20]. A pBABE-puro vector containing the cDNA encoding the human transferrin receptor with an HA-tag at its C- 
terminus was constructed by PCR using the oligos 5'GATCGGATCCGCCACCATGACCGGTATGGATCAAGCTAGATCAGCATTC and 3'GATCGTCGACCTCGAGTTACTCAGCATAATCAGGAACATCATAAGG

ATAATCGATCTCAAACTCATTGTCAATGTCCCAAACG. The sequence of the PCR part was verified by sequence analysis (Cogenics/Beckman Coulter).

\subsection{Cell culture}

As the 3T3-L1 preadipocytes originally obtained from ATCC appeared to be very heterologous and differentiated very poorly, an individual clone of cells was isolated from these preadipocytes and tested for growth, differentiation capacity, and insulin-induced GLUT4 translocation. Cultures of this clone contained at least 95\% adipocytes upon differentiation. 3T3-L1 preadipocytes were cultured, infected with retrovirus, and differentiated as described before [20]. For differentiation, preadipocytes were cultured for three days in DMEM/FBS, containing $700 \mathrm{nM}$ insulin, $0.5 \mathrm{mM}$ 3-isobutyl-1-methylxanthine (IBMX), $250 \mathrm{nM}$ dexamethasone, and $0.1 \mathrm{~g} / 1$ biotin. Unless stated otherwise, preadipocytes were differentiated in the absence of rosiglitazone. Adipocytes were used for experiments 8 to 12 days after onset of differentiation, with medium changed two days prior to the experiment. For the induction of insulin resistance, 3T3-L1 adipocytes were cultured for 24 hours in DMEM supplemented with $2 \mathrm{~g} / \mathrm{l} \mathrm{BSA}$ and $100 \mathrm{nM}$ insulin [21], followed by an extensive washing procedure, consisting of washing the wells with DMEM, supplemented with $20 \mathrm{mM}$ HEPES and $2 \mathrm{~g} / \mathrm{l}$ BSA, leaving the cells for 20 minutes in DMEM/HEPES/BSA, and repeating these two steps for an additional five times.

For all other experiments, cells were serum-starved for 2 hours in DMEM containing $2 \mathrm{~g} / \mathrm{l}$ BSA. 


\subsection{Fluorescence-based techniques}

The fluorescence-based assay for the detection of relative amounts of GLUT4 at the cell surface has been described in detail elsewhere [20]. Briefly, HA-GLUT4-expressing 3T3-L1 adipocytes grown in 96 well plates were fixed and immunolabeled using anti-HA antibody after the cells had been incubated in the absence or presence of the permeabilizing agent saponin to label GLUT4 at the cell surface or total cellular GLUT4, respectively. For microscopy, cell were incubated, fixed, and labeled as for the fluorescence-based assay. Nuclei were stained using TOPRO3. For the quantitative detection of endogenous GLUT4 and fat droplets in differentiating cells, non-infected (pre)adipocytes were cultured in black clear-bottom well plates and labeled with anti-GLUT4 1F8 antibody and $0.1 \mathrm{mg} / \mathrm{l}$ of the lipid stain nile red (within the same wells). Both anti-GLUT4 antibody and nile red displayed negligible background levels (evident from preadipocyte cultures). For quantitative analysis, the fluorescence signal related to HA(-GLUT4), GLUT4 and nile red was measured using the bottom-reading mode in a fluorescence microtiter plate reader (FLUOstar Galaxy, BMG Labtechnologies; Offenburg, Germany). Background fluorescence (preadipocytes) was subtracted from GLUT4 and nile red measurements. For microscopy, fluorescent label was visualized using a Zeiss LSM 510 confocal laser scanning microscope (Carl Zeiss, Göttingen, Germany) in the C3M MicorBio Cell Imaging Facility.

To measure GLUT4 internalization, a method adapted from [22] was used. Adipocytes were cultured on coverslips, differentiated, serum-starved, and incubated for 20 minutes with 100 $\mathrm{nM}$ insulin, upon which anti-HA antibody was added to the medium. After 1 to 4 minutes, the cells were washed extensively with ice-cold PBS on ice, fixed with paraformaldehyde, permeabilized with saponin and incubated with Alexa488-conjugated goat-anti-mouse 
antibody. Adipocytes were analyzed by epifluorescence microscopy using a 63X objective. The analysis was performed by quantifying all consecutive views along a horizontal line across the coverslip. The number of cells with intracellular label or label exclusively at the cell surface was determined for each view. The percentage of HA-positive cells with internalized label was determined for 5 consecutive views and averaged for at least $10 \times 5$ views. In total, these views represented more than 200 HA-positive cells.

\subsection{Glucose uptake}

Adipocytes, grown in 12 well plates, were incubated for 5 minutes in KRP/BSA $(12.5 \mathrm{mM}$ HEPES pH 7.4, $120 \mathrm{mM} \mathrm{NaCl}, 6 \mathrm{mM} \mathrm{KCl}, 1.2 \mathrm{mM} \mathrm{MgSO}_{4}, 1 \mathrm{mM} \mathrm{CaCl}_{2}, 0.4 \mathrm{mM} \mathrm{NaH} \mathrm{PO}_{4}$, $0.6 \mathrm{mM} \mathrm{Na} 2 \mathrm{HPO}_{4}, 2 \mathrm{~g} / \mathrm{l} \mathrm{BSA}$ ). Cells were treated or not with insulin for 20 minutes. To control cells, $50 \mu \mathrm{M}$ cytochalasin B was added and after 1 minute to all wells $0.1 \mathrm{mM}\left[{ }^{3} \mathrm{H}\right]-2-$ deoxy-glucose (10.4 kBq/well). After 3 minutes, the cells were extensively washed with icecold phosphate-buffered saline (PBS), lysed in $1 \%$ Triton X-100, and the radioactivity in the samples was determined using scintillation liquid Ultima Gold (PerkinElmer; Waltham, MA, USA) and a scintillation counter (Tricarb; Packard/PerkinElmer). All incubations up to the PBS washes were carried out at $37^{\circ} \mathrm{C}$. Cytochalasin B-treated cells were used to determine the assay background.

\subsection{Immunoblotting}

Cells were lysed in ice-cold PBS containing 1\% Triton X-100, and protease inhibitor cocktail Complete (Roche; Mannheim, Germany). Equal amounts of protein were mixed with gel loading buffer containing SDS (final concentration 2\%), subjected to SDS-PAGE and 
transferred to PVDF membrane. Membranes were incubated with the indicated antibodies. HRP-conjugated secondary antibodies were visualized using chemiluminescence reagent (PerkinElmer) and a CCD camera-based imager (LAS-3000, Fujifilm; Tokyo, Japan). Relative intensities were quantitated using MultiGauge software (Fujifilm).

\subsection{Statistics}

All data are presented as means \pm SD. Experiments were repeated at least three times. Representative experiments are shown. For 96 well plate and glucose uptake experiments, 4 wells and 3 wells were used for each data point, respectively. Comparisons between individual data sets were evaluated using two-tailed Student's $t$-tests and comparisons between dose-response curves were evaluated using F-tests (GraphPad Prism software). Doseresponse data were fitted based on a nonlinear four-parameter (variable slope) sigmoidal dose $(\log )$ - response curve according to the equation $\mathrm{Y}=$ bottom+(TopBottom $) /\left(1+10^{\wedge}((\operatorname{LogEC} 50-\mathrm{X}) *\right.$ HillSlope $\left.)\right)$. Differences between data sets were considered statistically different when $\mathrm{P}<0.05$. 


\section{Results}

\subsection{Rosiglitazone augments GLUT4 expression along adipocyte differentiation}

TZDs are known for their positive effect on the differentiation of preadipocytes into adipocytes. Remarkably, a detailed analysis of the enhancement of differentiation is lacking. To test TZD rosiglitazone in our cell system, we evaluated its effect on GLUT4 expression and lipid accumulation in 3T3-L1 (pre)adipocytes, differentiated with standard or suboptimal differentiation protocols (Fig. 1). Using a standard 3 day differentiation protocol $(700 \mathrm{nM}$ insulin, $500 \mu \mathrm{M}$ IBMX, and $250 \mathrm{nM}$ dexamethasone), virtually all preadipocytes differentiated well into adipocytes, as evidenced by the appearance of GLUT4 and nile redpositive fat droplets. Rosiglitazone did not seem to have any effect under these conditions. Serial dilution of the differentiation cocktail revealed that when insulin, IBMX, and dexamethasone concentrations were reduced to one eighth of the original concentrations, the cells stopped to differentiate (i.e. absence of GLUT4 and nile red signal). However, in this case, rosiglitazone restored differentiation. Rosiglitazone did not induce GLUT4 expression or lipid accumulation in the absence of insulin, IBMX, and dexamethasone. Quantitative analysis of GLUT4 expression and fat accumulation in cells treated with various concentrations of insulin, dexamethasone and IBMX revealed that rosiglitazone did not act on the differentiation process by enhancing insulin action, but that it enhanced the effects of IBMX and/or dexamethasone (Fig. 1B). Examining cells that had been exposed to one eighth of the differentiation cocktail and various concentrations of rosiglitazone demonstrated that fat accumulation was slightly more sensitive to rosiglitazone than GLUT4 expression (Fig. 2A). Half-maximal concentrations of rosiglitazone for fat accumulation and GLUT4 expression were $15 \mathrm{nM}$ and $27 \mathrm{nM}$, respectively. A small discrepancy between GLUT4 
expression and fat accumulation was also observed when the cells were treated for various time periods with differentiation cocktail in the absence or presence of rosiglitazone (Fig. 2B).

\subsection{Exposure of differentiating preadipocytes to rosiglitazone increases cell surface GLUT4 levels in fully differentiated adipocytes}

We evaluated the effect of early exposure of the cells to rosiglitazone (during differentiation) on cell surface GLUT4 levels in fully differentiated adipocytes (Fig. 3). Preadipocytes expressing HA-GLUT4 were incubated with a standard differentiation cocktail in the absence or presence of rosiglitazone for 2 to 5 days and cultured further in the absence of insulin, IBMX, dexamethasone, and rosiglitazone for a total of 11 days. Adipocytes were then treated or not for 20 minutes with $100 \mathrm{nM}$ insulin and cell surface GLUT4 levels were determined. The use of rosiglitazone during the differentiation process increased cell surface GLUT4 levels in the absence of insulin for all time periods tested and also for the three day differentiation condition with insulin stimulation (Fig. 3A). This led to a reduction in the relative effect of insulin on cell surface GLUT4 levels (Fig. 3B).

\subsection{Exposure of differentiated adipocytes to rosiglitazone increases basal cell surface GLUT4 levels and insulin sensitivity}

To determine whether the effect of rosiglitazone on GLUT4 in adipocytes is restricted to its presence during the differentiation process, we differentiated 3T3-L1 preadipocytes in the absence of rosiglitazone and treated the cells with rosiglitazone after differentiation (Fig. 4). This approach demonstrated that rosiglitazone gradually but largely augmented cell surface GLUT4 levels after up to five days of treatment (Fig. 4A). In contrast, cell surface GLUT4 
levels after acute insulin stimulation were comparable between control and rosiglitazonetreated adipocytes (Fig. 4A). Fluorescence confocal microscopy of control and rosiglitazonetreated adipocytes confirmed these results (Fig. 4B). Moreover, this increase in cell surface GLUT4 levels in basal but not insulin-stimulated cells was paralleled by increases in basal glucose uptake and an absence of increased glucose uptake under conditions where the cells were stimulated with high concentrations of insulin (Fig. 4C). Cells that were stimulated with submaximal concentrations of insulin $(1 \mathrm{nM})$ still displayed a rosiglitazone-induced augmentation of glucose uptake. Western blot analysis of rosiglitazone-treated cells revealed that the increase in glucose uptake could not be accounted for by an increase in GLUT4 expression. However, in accordance with previous studies [23], rosiglitazone increased the expression of the insulin receptor (Fig. 4D, E). The increase in cell surface GLUT4 levels was not specific to rosiglitazone as other TZD family members, pioglitazone and troglitazone, also displayed similar effects on GLUT4 (Fig. 4F).

Treatment of differentiated adipocytes for five days with various concentrations of rosiglitazone resulted in a dose response curve for cell surface GLUT4 expression with an EC50 value of $22 \mathrm{nM}$ and maximum effects at $0.5 \mu \mathrm{M}$ (Fig. 5A). This response was highly similar to that of preadipocytes regarding their rosiglitazone-enhanced differentiation (Fig. 2A). Acutely stimulating control- and rosiglitazone-treated adipocytes with various concentrations of insulin revealed that rosiglitazone not only augmented cell surface GLUT4 levels but also sensitized the 3T3-L1 adipocytes to insulin. Half-maximal insulin concentrations dropped from $0.90 \mathrm{nM}$ to $0.38 \mathrm{nM}(\mathrm{P}<0.0001)$ in adipocytes treated with rosiglitazone during the early phase of their differentiation (Fig. 5B) and from $0.76 \mathrm{nM}$ to $0.07 \mathrm{nM}(\mathrm{P}<0.05)$ in adipocytes treated with rosiglitazone after differentiation (Fig. 5C). 


\subsection{The effect of rosiglitazone on basal cell surface GLUT4 levels is long-lasting}

We next addressed the question whether rosiglitazone treatment of adipocytes induced a temporary effect on GLUT4 or whether this was a long-term (lasting) effect. Adipocytes were treated with rosiglitazone at various time periods before the analysis of cell surface GLUT4 levels, as indicated in Fig. 6A. Unfortunately, culturing the adipocytes for extended periods increased basal cell surface levels, even in the absence of rosiglitazone. Nevertheless, our study revealed that a 5 day rosiglitazone treatment followed by a rosiglitazone-free incubation period of 8 days was not different from a rosiglitazone treatment during the final 5 days (Fig. $6 B)$. This indicates that the effect of rosiglitazone on GLUT4 is long-lasting (irreversible during the time course of the experiment), likely due to a change in cell properties.

\subsection{Rosiglitazone also increases cell surface levels of the transferrin receptor}

To test whether the effect of rosiglitazone treatment is specific for GLUT4, we studied its effect on the transferrin receptor (TfR) (Fig. 7). While only $~ 50 \%$ of the intracellular GLUT4 pool is present in endosomes, cytoplasmic TfR is present exclusively in endosomes and therefore marks a subpopulation of the intracellular GLUT4-containing compartments [24]. To compare the TfR with GLUT4 using similar methodologies, we studied a TfR that was extracellularly tagged with an HA epitope. Immunofluorescence microscopy demonstrated that the localization of the tagged TfR was similar to the localization of endogenous TfR (Suppl. fig. S1). A quantitative analysis demonstrated that the TfR displayed quite a remarkable insulin-responsiveness (Fig. 7A). Though less pronounced than for GLUT4, the TfR translocated towards the cell surface in response to insulin. Similarly to GLUT4, the amount of TfR at the cell surface augmented with rosiglitazone (Fig. 7B), while the effects of 
rosiglitazone and insulin were not additive, indicating that the effect of rosiglitazone is not specific to GLUT4 and that rosiglitazone may augment endosomal recycling kinetics.

\subsection{Rosiglitazone does not affect GLUT4 internalization}

As rosiglitazone affects both GLUT4 and TfR, it is tempting to speculate that rosiglitazone alters cell surface GLUT4 levels by acting on its internalization rate. To test this possibility, adipocytes were incubated for 5 days in the presence or absence of $10 \mu \mathrm{M}$ rosiglitazone and internalization was measured (Fig. 8). Cells were incubated with anti-HA antibody for very short time periods to ensure that anti-HA-bound GLUT4 did not yet return to the cell surface after its internalization. Next, the percentage of cells with internalized label was determined. This revealed that rosiglitazone did not inhibit GLUT4 internalization, indicating that another step in the intracellular trafficking of GLUT4 (and of TfR) is altered by rosiglitazone.

\subsection{Rosiglitazone restores insulin-induced GLUT4 translocation in adipocytes that are} rendered insulin-resistant in vitro

TZDs have been studied for their potency in reversing insulin resistance in 3T3-L1 adipocytes. However, these studies have focused on the reversal of the reduction in insulininduced glucose uptake. Hence, it remains uncertain whether the TZD effects on insulin resistance can be accounted for by a change in the cellular expression of GLUT4, by an increase in cell surface GLUT4 levels, or by another mechanism. Therefore, we addressed the question whether rosiglitazone pretreatment could prevent the relative decrease in cell surface GLUT4 levels induced by a 24 hour insulin treatment (Fig. 9). This treatment clearly induced insulin resistance as a subsequent 20 minute stimulation of the cells with 1,10 , and $100 \mathrm{nM}$ 
insulin resulted in reduced cell surface GLUT4 levels compared to control cells (Fig. 9A). However, in rosiglitazone-treated adipocytes, acute insulin-induced GLUT4 translocation was not impaired by a 24 hour insulin pretreatment. As the insulin effects in rosiglitazone-treated cells are smaller compared to non-treated cells, we also examined the effects of shorter rosiglitazone treatments on reduced cell surface GLUT4 levels (Fig. 9B). This demonstrated that after two days of treatment, rosiglitazone completely restored acute insulin responsiveness of GLUT4 translocation in cells subjected to a 24 hour insulin incubation, without largely enhancing basal cell surface levels. These data indicate that rosiglitazone augments basal cell surface GLUT4 levels and independently restores the response of GLUT4 to insulin stimulation under conditions that induce insulin resistance. To evaluate whether rosiglitazone rescues the decrease in GLUT4 expression that has been associated with insulin resistance in vivo and in vitro [21,25], we treated adipocytes for three days with or without insulin and rosiglitazone. This demonstrated that the insulin-induced downregulation of GLUT4 expression ( $\sim 50 \%$ after three days) is not rescued by rosiglitazone (Fig. 9C). Furthermore, our studies demonstrated that reductions in GLUT4 expression due to TNF- $\alpha$ treatment are not rescued by rosiglitazone either (data not shown). 


\section{Discussion}

While adipose tissue is not the main storage site for glucose in the postprandial state, glucose metabolism in this organ is essential for whole body glucose homeostasis, via a direct regulation of the synthesis and secretion of adipokines that have important effects in other parts of the body. Adipocyte-specific knock-out of GLUT4 results in insulin resistance in muscle and liver and an enhanced secretion of adipokines, amongst which serum retinol binding protein 4 (RBP4) [26, 27]. RBP4 levels have been demonstrated to be elevated in insulin resistance and T2D. Moreover, its overexpression causes insulin resistance while its genetic deletion enhances insulin sensitivity. Interestingly, rosiglitazone has been shown to restore serum RBP4 levels in insulin resistant mice [27]. Given that both GLUT4 and rosiglitazone regulate adipokine secretion, adipocytic GLUT4 could very well be implicated in the rosiglitazone-induced adipokine-dependent amelioration of whole body glucose homeostasis in T2D.

Our results support this hypothesis as they show that rosiglitazone increases basal cell surface GLUT4 levels and glucose uptake by adipocytes. In addition to its enhancement of GLUT4 expression throughout adipocyte differentiation, this TZD augmented the amount of GLUT4 at the plasma membrane of adipocytes when administered either during (pre)adipocyte differentiation or afterwards. So, even while the time-scale of the effect of insulin and rosiglitazone on GLUT4 traffic are distinct, rosiglitazone clearly partially mimics insulin action. Moreover, even when administered after the cells had been fully differentiated, its effect on GLUT4 was irreversible, suggesting that rosiglitazone changes adipocyte properties. Possibly, rosiglitazone, via its interaction with transcription factor PPAR $\gamma$, may change the expression of one or several proteins that play a regulatory role in endosomal recycling such 
as rab, SNARE, or sorting nexin proteins [28, 29]. In support of this, the rosiglitazoneinduced effects on GLUT4 required several days of treatment. In contrast, troglitazone has been shown to largely alter cell surface GLUT4 levels in muscle and fat cells within 15 and 24 hours of treatment, respectively [30, 31]. Troglitazone concentrations that were found to increase cell surface GLUT4 levels in these studies were much higher than the concentrations of rosiglitazone we found to be effective, but this correlates well with the lower affinity of troglitazone for PPAR $\gamma[32,33]$. Neither in muscle cells [30] nor in adipocytes [31, 34] (Fig. $3 \mathrm{~A}, \mathrm{C})$ were the effects of glitazones and high concentrations of insulin additive. However, rosiglitazone treatment of $o b / o b$ mice has been reported to increase glucose uptake and cell surface GLUT4 levels in primary adipocytes stimulated with insulin ex vivo, but this was most probably due to an increase in GLUT4 expression [16]. Basal cell surface GLUT4 levels were found to be increased by troglitazone in L6 muscle cells [30] and primary adipocytes [31], and by rosiglitazone and troglitazone in 3T3-L1 adipocytes (this study). Furthermore, troglitazone was found to induce a significant (50\%) increase in GLUT4 expression levels in adipocytes [31], while this was not the case for rosiglitazone in our studies.

Our studies have suggested that the effect of rosiglitazone is not specific for GLUT4, as rosiglitazone also increased basal but not insulin-enhanced cell surface levels of the transferrin receptor (TfR). The predominantly endosome-localized TfR is constitutively recycling towards the plasma membrane, while its recycling kinetics are increased even further upon acute insulin stimulation [35]. As both GLUT4 and TfR surface levels are increased upon rosiglitazone treatment, we propose that rosiglitazone increases endosomal recycling kinetics. For GLUT4 this increase is quite dramatic, as GLUT4 recycles extremely slowly in non-stimulated cells $[36,37]$. As the rosiglitazone effects appear not to be further enhanced by insulin, similar molecular systems involved in endosomal recycling may be 
implicated in the long-term rosiglitazone effects and in acute insulin action. The rosiglitazoneinduced increase in the expression of the insulin receptor (Fig. 3D) could imply an activation of the insulin signaling cascade under basal conditions. However, neither the insulin receptor nor its downstream effector Akt were phosphorylated under basal conditions in rosiglitazonetreated adipocytes (data not shown). Our data demonstrate that the increase in cell surface GLUT4 levels is not due to changes in its internalization rate. In contrast, metformin has been demonstrated to inhibit GLUT4 endocytosis and thereby to augment insulin-induced increases in the amount of GLUT4 at the plasma membrane [38], which is clearly different from our findings. Since rosiglitazone, as well as other TZDs, affect the synthesis and secretion of adipokine/cytokines, such as adiponectin [39], RBP4 [27], leptin [40], Il-6 [41], and TNF- $\alpha$ [42], it cannot be excluded that the effect on endosomal recycling is mediated in part via an alteration in adipokine secretion (autocrine effect). Alternatively, this effect on endocytic recycling could be mediated (in part) via annexin II, which is involved in insulin-induced GLUT4 translocation, and whose expression levels are elevated upon troglitazone treatment [34]. Finally, TZDs might enhance endosomal recycling via altering intracellular ROS (reactive oxygen species) levels, as TZDs have been shown to display antioxidant properties [19].

These antioxidant properties may also be implicated in the effects of rosiglitazone on GLUT4 in insulin resistance. Previously, the reduction in glucose uptake in insulin-resistant 3T3-L1 adipocytes has been shown to be suppressed by ROS scavenger MnTBAP as well as by rosiglitazone, while rosiglitazone decreased intracellular ROS as effectively as MnTBAP [8, 19]. However, it is unclear whether the TZD-mediated restoration of glucose uptake was mediated via a change in glucose transporter expression level or via restoration of the rate of insulin-induced GLUT4 translocation. Our studies indicate that rosiglitazone completely 
restores the response of GLUT4 to insulin stimulation under conditions that normally induce insulin resistance. This was already evident after two days of rosiglitazone treatment, before major changes in basal cell surface GLUT4 levels occurred. This effect is likely to be mediated via a restoration of insulin signaling [43] and possibly due to an increase in the expression of the insulin receptor (Fig. 3). It has been reported that in primary adipocytes from rosiglitazone-treated $o b / o b$ mice GLUT4 expression is increased, concurrent with an increase in cell surface GLUT4 levels under conditions of insulin stimulation [16]. However, our studies have demonstrated that the reduction in GLUT4 expression that is associated with insulin resistance is not reversed by rosiglitazone, suggesting that at least in adipocytes rendered insulin-resistant in vitro, rosiglitazone acts mainly on GLUT4 translocation and not on GLUT4 expression.

In conclusion, using the 3T3-L1 adipocyte cell model, we have investigated for the first time the effects of rosiglitazone on GLUT4 in vitro and have demonstrated that treatment of adipocytes for several days with rosiglitazone results in an irreversible effect on endosomal protein traffic, in an augmentation of GLUT4 at the PM, and in an increased glucose uptake. A second, independent effect of rosiglitazone was seen in insulin resistant cells, where it fully restored insulin-induced GLUT4 translocation. While it remains to be determined by which molecular mechanisms rosiglitazone affects endosomal GLUT4 recycling and GLUT4 insulin-sensitivity in insulin resistance, these effects are likely to contribute to the rosiglitazone-mediated enhancement of glucose homeostasis in vivo. 


\section{Acknowledgments}

We thank Rytis Prekeris for anti-syntaxin13 antibody, Hartmut Land for pBABE vector, Toshio Kitamura for Plat-E cells, and Alain Ktorza (Institut de Recherches Servier, Suresnes, France) for helpful suggestions, and acknowledge the C3M MicorBio Cell Imaging Facility. This work was supported by the Institut National de la Santé et de la Recherche Médicale (INSERM) and the University of Nice-Sophia-Antipolis, the Conseil Régional ProvenceAlpes-Côte d'Azur, and the Conseil Général des Alpes Maritimes. RG is a recipient of an INSERM Avenir grant and LM is supported by an INSERM/Région Provence-Alpes-Côte d'Azur/Servier grant. 


\section{References}

[1] Martens FM, Visseren FL, Lemay J, de Koning EJ, Rabelink TJ. Metabolic and additional vascular effects of thiazolidinediones. Drugs 2002;62:1463-80.

[2] Wilding J. Thiazolidinediones, insulin resistance and obesity: Finding a balance. Int J Clin Pract 2006;60:1272-80.

[3] Ceriello A. Thiazolidinediones as anti-inflammatory and anti-atherogenic agents. Diabetes Metab Res Rev 2008;24:14-26.

[4] Spiegelman BM. PPAR-gamma: adipogenic regulator and thiazolidinedione receptor. Diabetes 1998;47:507-14.

[5] Hallakou S, Doare L, Foufelle F, Kergoat M, Guerre-Millo M, Berthault MF, et al. Pioglitazone induces in vivo adipocyte differentiation in the obese Zucker fa/fa rat. Diabetes 1997;46:1393-9.

[6] Hallakou S, Foufelle F, Doare L, Kergoat M, Ferre P. Pioglitazone-induced increase of insulin sensitivity in the muscles of the obese Zucker fa/fa rat cannot be explained by local adipocyte differentiation. Diabetologia 1998;41:963-8.

[7] Ohsumi J, Sakakibara S, Yamaguchi J, Miyadai K, Yoshioka S, Fujiwara T, et al. Troglitazone prevents the inhibitory effects of inflammatory cytokines on insulininduced adipocyte differentiation in 3T3-L1 cells. Endocrinology 1994;135:2279-82.

[8] Szalkowski D, White-Carrington S, Berger J, Zhang B. Antidiabetic thiazolidinediones block the inhibitory effect of tumor necrosis factor-alpha on differentiation, insulin-stimulated glucose uptake, and gene expression in 3T3-L1 cells. Endocrinology 1995;136:1474-81.

[9] Barak Y, Nelson MC, Ong ES, Jones YZ, Ruiz-Lozano P, Chien KR, et al. PPAR gamma is required for placental, cardiac, and adipose tissue development. Mol Cell 1999;4:585-95.

[10] Tamori Y, Masugi J, Nishino N, Kasuga M. Role of peroxisome proliferator-activated receptor-gamma in maintenance of the characteristics of mature 3T3-L1 adipocytes. Diabetes 2002;51:2045-55.

[11] Hammarstedt A, Sopasakis VR, Gogg S, Jansson PA, Smith U. Improved insulin sensitivity and adipose tissue dysregulation after short-term treatment with pioglitazone in non-diabetic, insulin-resistant subjects. Diabetologia 2005;48:96-104.

[12] Martin G, Schoonjans K, Staels B, Auwerx J. PPARgamma activators improve glucose homeostasis by stimulating fatty acid uptake in the adipocytes. Atherosclerosis 1998;137:S75-80.

[13] Chao L, Marcus-Samuels B, Mason MM, Moitra J, Vinson C, Arioglu E, et al. Adipose tissue is required for the antidiabetic, but not for the hypolipidemic, effect of thiazolidinediones. J Clin Invest 2000;106:1221-8.

[14] Albrektsen T, Frederiksen KS, Holmes WE, Boel E, Taylor K, Fleckner J. Novel genes regulated by the insulin sensitizer rosiglitazone during adipocyte differentiation. Diabetes 2002;51:1042-51.

[15] Furuta M, Yano Y, Gabazza EC, Araki-Sasaki R, Tanaka T, Katsuki A, et al. Troglitazone improves GLUT4 expression in adipose tissue in an animal model of obese type 2 diabetes mellitus. Diabetes Res Clin Pract 2002;56:159-71.

[16] Young PW, Cawthorne MA, Coyle PJ, Holder JC, Holman GD, Kozka IJ, et al. Repeat treatment of obese mice with BRL 49653, a new potent insulin sensitizer, enhances insulin action in white adipocytes. Association with increased insulin 
binding and cell-surface GLUT4 as measured by photoaffinity labeling. Diabetes 1995;44:1087-92.

[17] Stevenson RW, McPherson RK, Persson LM, Genereux PE, Swick AG, Spitzer J, et al. The antihyperglycemic agent englitazone prevents the defect in glucose transport in rats fed a high-fat diet. Diabetes 1996;45:60-6.

[18] Weinstein SP, Holand A, O'Boyle E, Haber RS. Effects of thiazolidinediones on glucocorticoid-induced insulin resistance and GLUT4 glucose transporter expression in rat skeletal muscle. Metabolism 1993;42:1365-9.

[19] Houstis N, Rosen ED, Lander ES. Reactive oxygen species have a causal role in multiple forms of insulin resistance. Nature 2006;440:944-8.

[20] Govers R, James DE, Coster AC. High-throughput analysis of the dynamics of recycling cell surface proteins. Methods Mol Biol 2008;440:129-46.

[21] Maier VH, Gould GW. Long-term insulin treatment of 3T3-L1 adipocytes results in mis-targeting of GLUT4: implications for insulin-stimulated glucose transport. Diabetologia 2000;43:1273-81.

[22] Williams D, Hicks SW, Machamer CE, Pessin JE. Golgin-160 is required for the Golgi membrane sorting of the insulin-responsive glucose transporter GLUT4 in adipocytes. Mol Biol Cell 2006;17:5346-55.

[23] Hernandez R, Teruel T, Lorenzo M. Rosiglitazone produces insulin sensitisation by increasing expression of the insulin receptor and its tyrosine kinase activity in brown adipocytes. Diabetologia 2003;46:1618-28.

[24] Livingstone C, James DE, Rice JE, Hanpeter D, Gould GW. Compartment ablation analysis of the insulin-responsive glucose transporter (GLUT4) in 3T3-L1 adipocytes. Biochem J 1996;315:487-95.

[25] Shepherd PR, Kahn BB. Glucose transporters and insulin action--implications for insulin resistance and diabetes mellitus. N Engl J Med 1999;341:248-57.

[26] Abel ED, Peroni O, Kim JK, Kim YB, Boss O, Hadro E, et al. Adipose-selective targeting of the GLUT4 gene impairs insulin action in muscle and liver. Nature 2001;409:729-33.

[27] Yang Q, Graham TE, Mody N, Preitner F, Peroni OD, Zabolotny JM, et al. Serum retinol binding protein 4 contributes to insulin resistance in obesity and type 2 diabetes. Nature 2005;436:356-62.

[28] Cai H, Reinisch K, Ferro-Novick S. Coats, tethers, Rabs, and SNAREs work together to mediate the intracellular destination of a transport vesicle. Dev Cell 2007;12:67182.

[29] van Kerkhof P, Lee J, McCormick L, Tetrault E, Lu W, Schoenfish M, et al. Sorting nexin 17 facilitates LRP recycling in the early endosome. Embo J 2005;24:2851-61.

[30] Yonemitsu S, Nishimura H, Shintani M, Inoue R, Yamamoto Y, Masuzaki H, et al. Troglitazone induces GLUT4 translocation in L6 myotubes. Diabetes 2001;50:1093101.

[31] Shintani M, Nishimura H, Yonemitsu S, Ogawa Y, Hayashi T, Hosoda K, et al. Troglitazone not only increases GLUT4 but also induces its translocation in rat adipocytes. Diabetes 2001;50:2296-300.

[32] Adams M, Montague CT, Prins JB, Holder JC, Smith SA, Sanders L, et al. Activators of peroxisome proliferator-activated receptor gamma have depot-specific effects on human preadipocyte differentiation. J Clin Invest 1997;100:3149-53.

[33] Camp HS, Li O, Wise SC, Hong YH, Frankowski CL, Shen X, et al. Differential activation of peroxisome proliferator-activated receptor-gamma by troglitazone and rosiglitazone. Diabetes 2000;49:539-47. 
[34] Huang J, Hsia SH, Imamura T, Usui I, Olefsky JM. Annexin II is a thiazolidinedioneresponsive gene involved in insulin-induced glucose transporter isoform 4 translocation in 3T3-L1 adipocytes. Endocrinology 2004;145:1579-86.

[35] Foran PG, Fletcher LM, Oatey PB, Mohammed N, Dolly JO, Tavare JM. Protein kinase B stimulates the translocation of GLUT4 but not GLUT1 or transferrin receptors in 3T3-L1 adipocytes by a pathway involving SNAP-23, synaptobrevin-2, and/or cellubrevin. J Biol Chem 1999;274:28087-95.

[36] Govers R, Coster AC, James DE. Insulin increases cell surface GLUT4 levels by dose dependently discharging GLUT4 into a cell surface recycling pathway. Mol Cell Biol 2004;24:6456-66.

[37] Karylowski O, Zeigerer A, Cohen A, McGraw TE. GLUT4 is retained by an intracellular cycle of vesicle formation and fusion with endosomes. Mol Biol Cell 2004;15:870-82.

[38] Yang J, Holman GD. Long-term metformin treatment stimulates cardiomyocyte glucose transport through an AMP-activated protein kinase-dependent reduction in GLUT4 endocytosis. Endocrinology 2006;147:2728-36.

[39] Maeda N, Takahashi M, Funahashi T, Kihara S, Nishizawa H, Kishida K, et al. PPARgamma ligands increase expression and plasma concentrations of adiponectin, an adipose-derived protein. Diabetes 2001;50:2094-9.

[40] Nolan JJ, Olefsky JM, Nyce MR, Considine RV, Caro JF. Effect of troglitazone on leptin production. Studies in vitro and in human subjects. Diabetes 1996;45:1276-8.

[41] Lagathu C, Bastard JP, Auclair M, Maachi M, Capeau J, Caron M. Chronic interleukin-6 (IL-6) treatment increased IL-6 secretion and induced insulin resistance in adipocyte: prevention by rosiglitazone. Biochem Biophys Res Commun 2003;311:372-9.

[42] Okuno A, Tamemoto H, Tobe K, Ueki K, Mori Y, Iwamoto K, et al. Troglitazone increases the number of small adipocytes without the change of white adipose tissue mass in obese Zucker rats. J Clin Invest 1998;101:1354-61.

[43] Peraldi P, Xu M, Spiegelman BM. Thiazolidinediones block tumor necrosis factoralpha-induced inhibition of insulin signaling. J Clin Invest 1997;100:1863-9. 


\section{Figure legends}

Fig. 1. Effect of rosiglitazone on GLUT4 expression and fat accumulation during 3T3-L1 preadipocyte differentiation. (A) 3T3-L1 preadipocytes were treated for three days with differentiation cocktail containing the indicated concentrations of insulin (ins), IBMX, and dexamethasone (dex) in the absence or presence of $10 \mu \mathrm{M}$ rosiglitazone and simultaneously stained for endogenous GLUT4 (anti-GLUT4 immunostaining), lipid droplets (nile red), and nuclei (TOPRO3). Label is analyzed by confocal fluorescence microscopy. Bar, $5 \mu \mathrm{m}$. (B) Adipocytes cultured in 96 well plates were treated and labeled as described for (A), but fluorescence was quantified using a fluorescence microtiter plate reader. Each well was used for both GLUT4 and lipid measurements. The amount of GLUT4 and lipid in adipocytes differentiated using the standard differentiation protocol (700 nM insulin, $500 \mu \mathrm{M}$ IBMX, and $250 \mathrm{nM}$ dexamethasone) was set to $100 \%$. Note that rosiglitazone increased GLUT4 expression and lipid accumulation by enhancing the effects of IBMX and/or dexamethasone. The absence of a dominant role for insulin in the differentiation process (in the absence and presence of rosiglitazone) cannot be explained by the presence of insulin in the sera, as the concentration of insulin in the culture medium was as low as $3 \mathrm{pM}$.

Fig. 2. Effect of varying the concentration and length of rosiglitazone treatment on GLUT4 expression and lipid accumulation. (A) 3T3-L1 preadipocytes were exposed for three days to differentiation medium containing $88 \mathrm{nM}$ insulin, $62 \mu \mathrm{M}$ IBMX, $32 \mathrm{nM}$ dexamethasone and different concentrations of rosiglitazone. The amount of GLUT4 and lipid in cells 8 days after the onset of differentiation was quantitated as described in the legend of fig. S1. EC50 values of rosiglitazone for fat accumulation and GLUT4 expression were $15 \mathrm{nM}$ and $27 \mathrm{nM}$, respectively $(\mathrm{P}<0.0001)$. (B) 3T3-L1 preadipocytes were exposed for the indicated time 
periods to either one fourth (175 $\mathrm{nM}$ insulin, $125 \mu \mathrm{M}$ IBMX, and $62 \mathrm{nM}$ dexamethasone) or half of the standard differentiation cocktail (350 nM insulin, $250 \mu \mathrm{M}$ IBMX, and $125 \mathrm{nM}$ dexamethasone) in the absence or presence of $10 \mu \mathrm{M}$ rosiglitazone. Cells were cultured further to a total of 8 days and GLUT4 and lipid was quantitated. Note the subtle differences in the kinetics of the increases in GLUT4 and lipid, which is most evident at 36 and 72 hours of treatment (dashed lines).

Fig. 3. Changes in cell surface GLUT4 levels in 3T3-L1 adipocytes differentiated in the presence of rosiglitazone. (A) 3T3-L1 preadipocytes were exposed for 2 to 5 days to differentiation medium containing $700 \mathrm{nM}$ insulin, $500 \mu \mathrm{M}$ IBMX, $250 \mathrm{nM}$ dexamethasone, and rosiglitazone $(10 \mu \mathrm{M})$ or vehicle, and further incubated in DMEM/FBS without additives. Upon incubation of fully differentiated cells for $20 \mathrm{~min}$ in the absence or presence of $100 \mathrm{nM}$ insulin, the relative amount of cell surface GLUT4 was determined. Cells exposed for 2 days to differentiation medium without rosiglitazone did not differentiate well and are therefore left out of comparison. (B) The ratio of cell surface GLUT4 levels in the presence and absence of insulin (fold translocation) was calculated from the data presented in (A). *P<0.0001.

Fig. 4. Effect of rosiglitazone treatment of differentiated adipocytes on cell surface GLUT4 levels. (A) Differentiated 3T3-L1 adipocytes were exposed for up to 5 days to $10 \mu \mathrm{M}$ rosiglitazone and the relative amount of cell surface GLUT4 before and after an acute $20 \mathrm{~min}$ stimulation with $100 \mathrm{nM}$ insulin was determined. Basal cell surface GLUT4 levels were significantly different from control cells after two days of treatment (B) Control adipocytes and adipocytes expressing HA-GLUT4 were treated for 5 days with $10 \mu \mathrm{M}$ rosiglitazone or vehicle, fixed, immunolabeled with anti-HA antibody, and analyzed by fluorescence microscopy. Rosiglitazone increased basal cell surface GLUT4 level and no specific label was 
detected in control adipocytes. (C) Adipocytes treated for 5 days with rosiglitazone or vehicle were incubated for $20 \mathrm{~min}$ in the absence or presence of 1 and $100 \mathrm{nM}$ insulin and glucose transport activity was measured (expressed as $\mu \mathrm{mol} 2$-DOG per g cellular protein per minute). (D) Differentiated adipocytes were treated for up to 5 days with rosiglitazone and the expression of GLUT4, insulin receptor (IR), and tubulin in adipocyte lysates was determined by Western blot. (E) Relative amounts of GLUT4 and insulin receptor were quantitated from Western blots and expressed as percentage of untreated cells. (F) Adipocytes treated for 5 days with $10 \mu \mathrm{M}$ of rosiglitazone, pioglitazone, or troglitazone were incubated for $20 \mathrm{~min}$ with the indicated concentrations of insulin and the amount of GLUT4 at the cell surface was determined. $* \mathrm{P}<0.001 ; * * \mathrm{P}<0.0001$, compared to non-treated control cells.

Fig. 5. Dose response curves of rosiglitazone and insulin on cell surface GLUT4 levels in 3T3-L1 adipocytes. (A) Differentiated 3T3-L1 adipocytes were exposed for 5 days to various concentrations of rosiglitazone and the relative amount of cell surface GLUT4 was determined after an acute $20 \mathrm{~min}$ stimulation with or without $100 \mathrm{nM}$ insulin. EC50 of rosiglitazone for the increase in basal cell surface levels is $22 \mathrm{nM}$. (B) 3T3-L1 preadipocytes were exposed to $10 \mu \mathrm{M}$ rosiglitazone during the first three days of differentiation and further cultured in the absence of rosiglitazone. Fully differentiated adipocytes were treated with various concentrations of insulin. The increase in cell surface GLUT4 levels was determined and expressed as percentage of the maximum insulin effect. (C) Fully differentiated adipocytes were exposed to $10 \mu \mathrm{M}$ rosiglitazone for 5 days and treated with insulin as under (B). EC50 of insulin on cell surface GLUT4 levels when differentiation was induced in the absence or presence of rosiglitazone was 0.90 and $0.38 \mathrm{nM}$, respectively $(\mathrm{P}<0.0001)$, while rosiglitazone treatment after differentiation reduced the EC50 from $0.76 \mathrm{nM}$ to $0.07 \mathrm{nM}$ 
$(\mathrm{P}<0.05)$. Note that the relatively large error bars in $(\mathrm{C})$ ' + rosi' are due to the relative small insulin effect in rosiglitazone-treated adipocytes.

Fig. 6. Irreversibility of the effects of rosiglitazone on GLUT4 cell surface levels. (A) Schematic overview of two distinct rosiglitazone treatments of 3T3-L1 adipocytes. Black box represents differentiation stage (treatment with differentiation cocktail). (B) GLUT4 cell surface levels were determined in adipocytes treated according to (A). Basal cell surface GLUT4 levels were higher than usual due to the increase in the age of the cells. Basal cell surface GLUT4 levels in II and III are not significantly different, while both are different from basal levels in $\mathrm{I}(\mathrm{P}<0.0001)$.

Fig. 7. The intracellular traffic of the transferrin receptor is affected by rosiglitazone in adipocytes. (A) Adipocytes expressing HA-GLUT4 and HA-TfR were incubated for various times with $100 \mathrm{nM}$ insulin and cell surface levels were determined for both proteins. (B) Differentiated adipocytes expressing HA-TfR were treated for up to 5 days with $10 \mu \mathrm{M}$ rosiglitazone, and its cell surface levels in the presence and absence of $100 \mathrm{nM}$ insulin were determined. Basal cell surface TfR levels were significantly different from control cells after two days of rosiglitazone treatment.

Fig. 8. Rosiglitazone does not impair GLUT4 internalization. Insulin-stimulated HA-GLUT4expressing adipocytes, cultured for 5 days in the absence or presence of $10 \mu \mathrm{M}$ rosiglitazone, were incubated for 1,2 , or 4 minutes with anti-HA antibody and immediately washed with ice-cold PBS. Cells were immunolabeled with fluorescent secondary antibody and the percentage of HA-positive cells that displayed internalized (perinuclear) HA label was determined. 
Fig. 9. Rosiglitazone prevents reduced cell surface GLUT4 levels in insulin resistance. (A) Adipocytes were incubated for 5 days in the absence or presence of rosiglitazone. During the final 24 hours, the cells were subjected to $100 \mathrm{nM}$ insulin to induce insulin resistance or left untreated. After the five day treatment, cells were stimulated for 20 min with the indicated concentrations of insulin and cell surface GLUT4 levels were determined. (B) Adipocytes were cultured with rosiglitazone for 0 to 5 days, subjected or not to 24 hours of $100 \mathrm{nM}$ insulin, and incubated for 20 minutes in the absence or presence of $1 \mathrm{nM}$ insulin. Relative cell surface GLUT4 levels were determined. (C) 3T3-L1 adipocytes were incubated for three days in DMEM supplemented with $1 \%$ FBS with or without $10 \mu \mathrm{M}$ rosiglitazone and $100 \mathrm{nM}$ insulin. Cell lysates were subjected to PAGE and transferred to PVDF membrane. Membranes were labeled with antibody or stained with ponceau S to visualize GLUT4 and the total cellular protein pool, respectively. Ponceau S stain confirms that equal amounts of protein were loaded on gel. $* \mathrm{P}<0.001$ and $* * \mathrm{P}<0.0001$, compared to cells not subjected to 24 hours of insulin treatment. 


\section{Supplementary material}

Fig. S1. Ectopic HA-tagged transferrin receptor is properly localized. (A) Control 3T3-L1 adipocytes were labeled for transferrin receptor (TfR) and syntaxin13 (syn13). The merge panel shows the overlap in localization between the two proteins (in yellow). (B) HA-tagged transferrin receptor (HA-TfR) was expressed in 3T3-L1 adipocytes and its localization was analyzed by co-labeling of the cells with anti-syntaxin 13 antibody. Bar, $10 \mu \mathrm{m}$. 
A
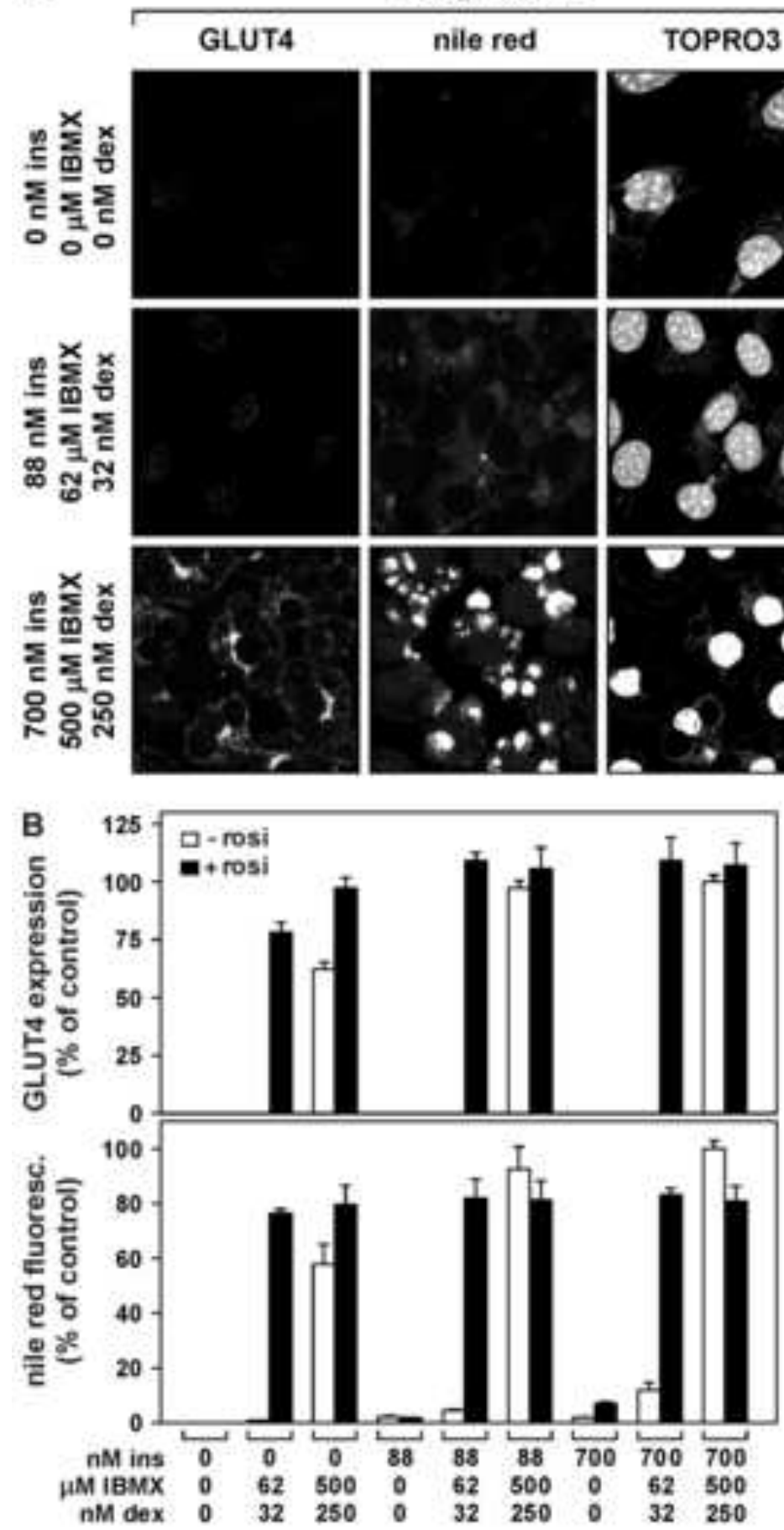

+ rosiglitazone

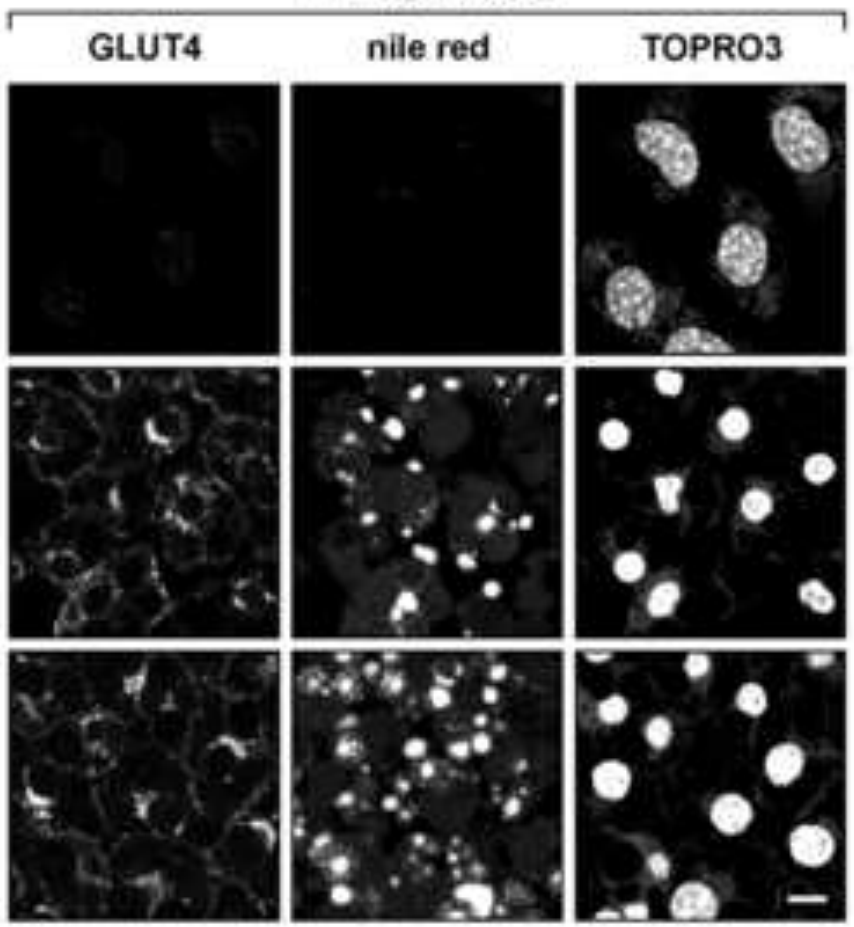

Martinez et al - Figure 1 

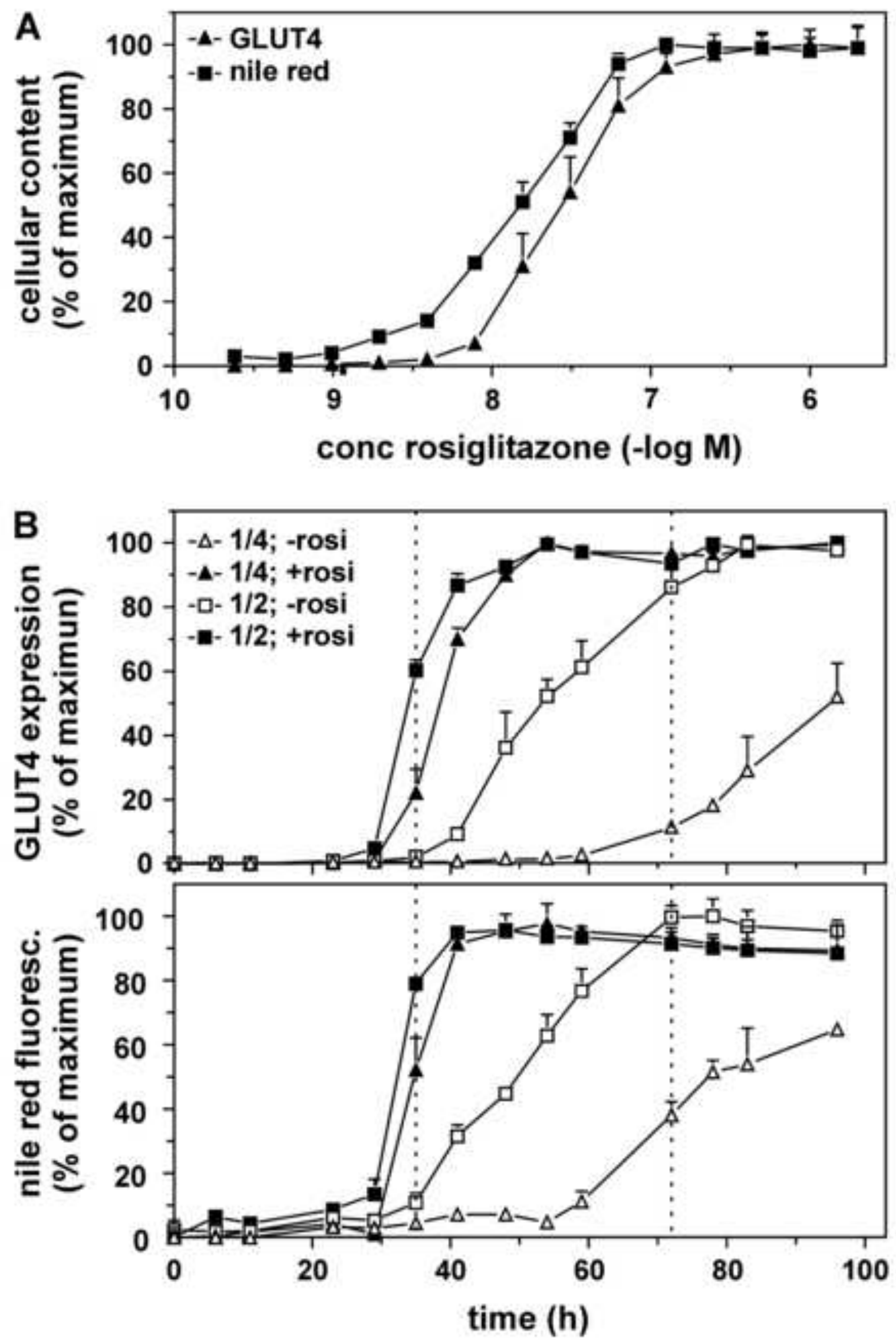

Martinez et al - Figure 2 


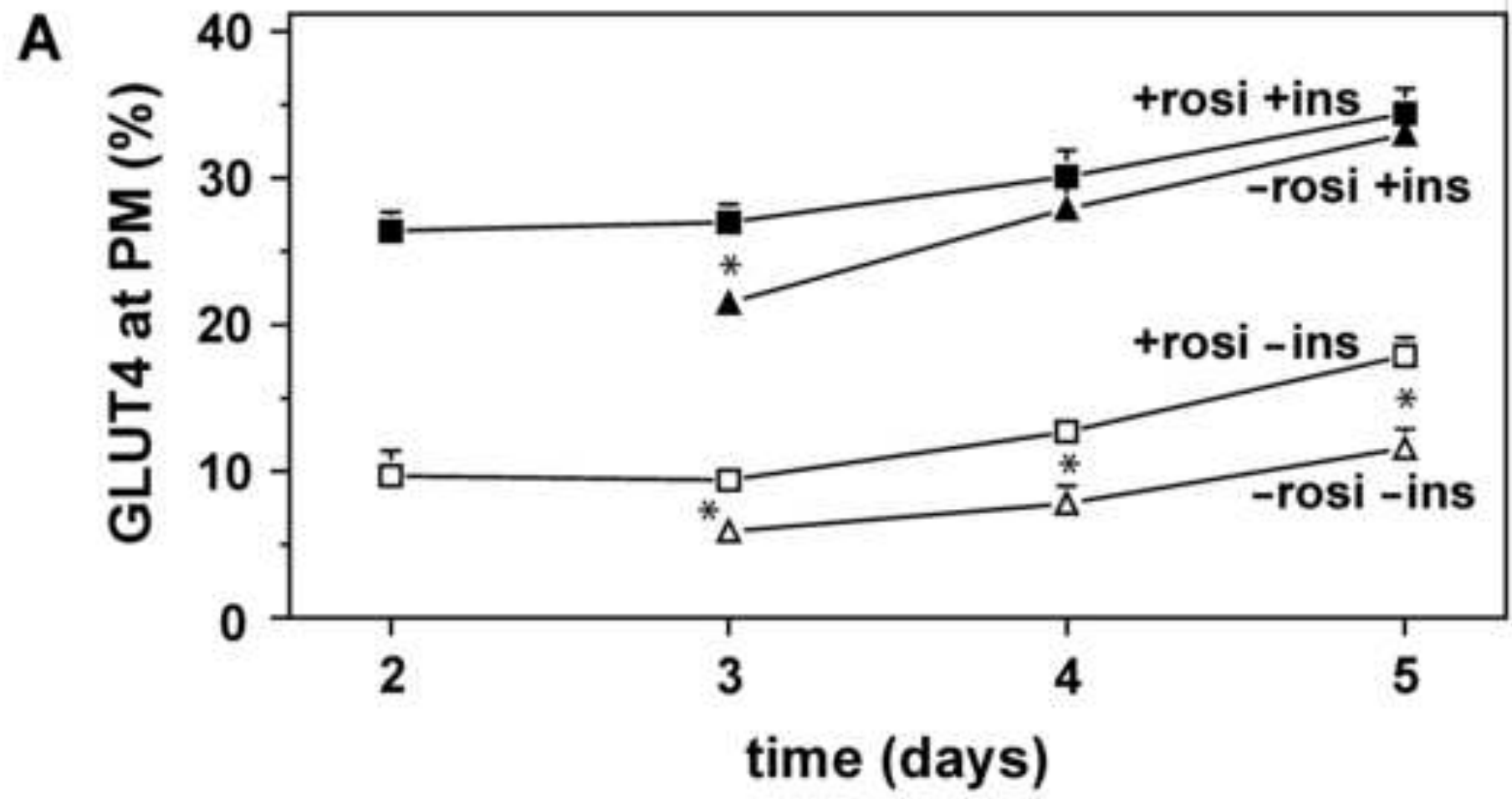

B

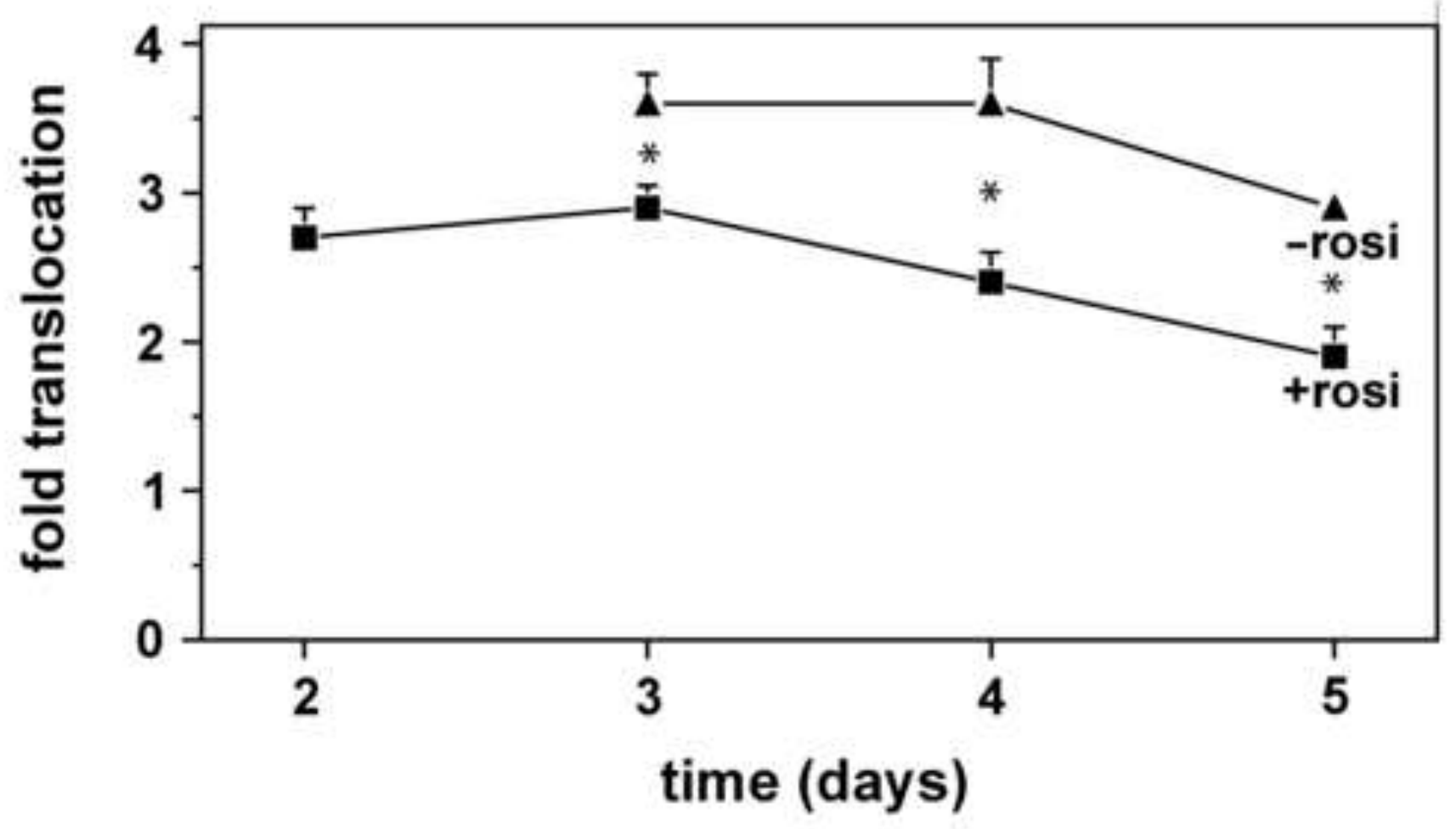

Martinez et al - Figure 3 


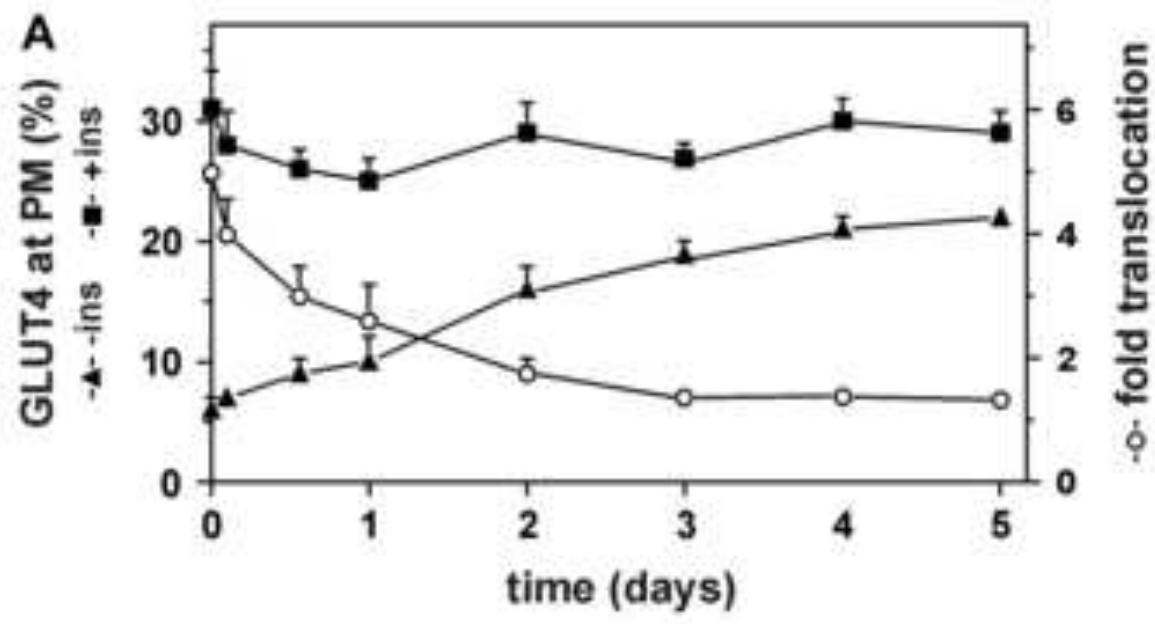

B

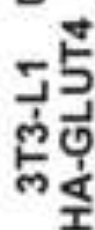

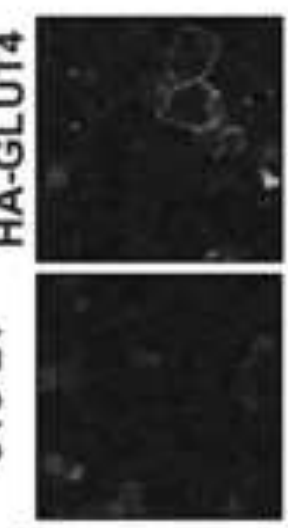

rosi
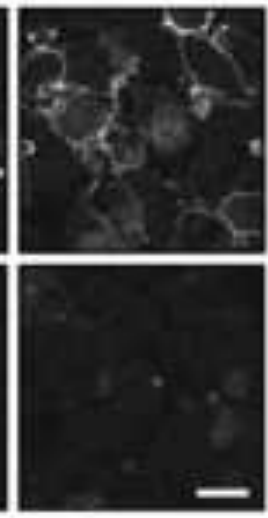

$+$
C

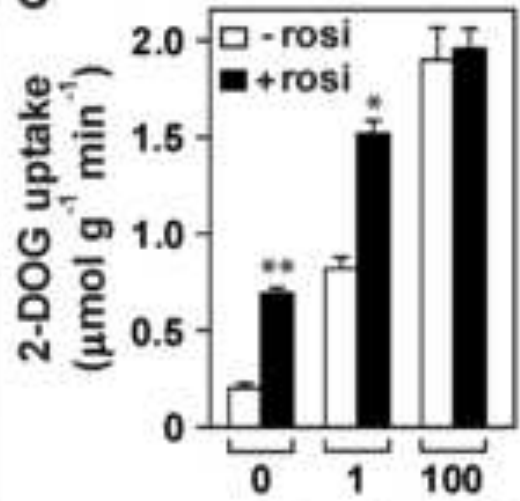

conc insulin (nM)

D

$$
\begin{array}{|llllll}
\multicolumn{5}{c}{\text { days rosi }} \\
\hline \begin{array}{llllll}
1 & 1 & 2 & 3 & 4 & 5
\end{array}
\end{array}
$$

GLUT4

Ever

IR

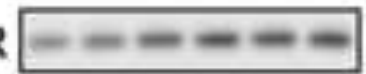

tubulin
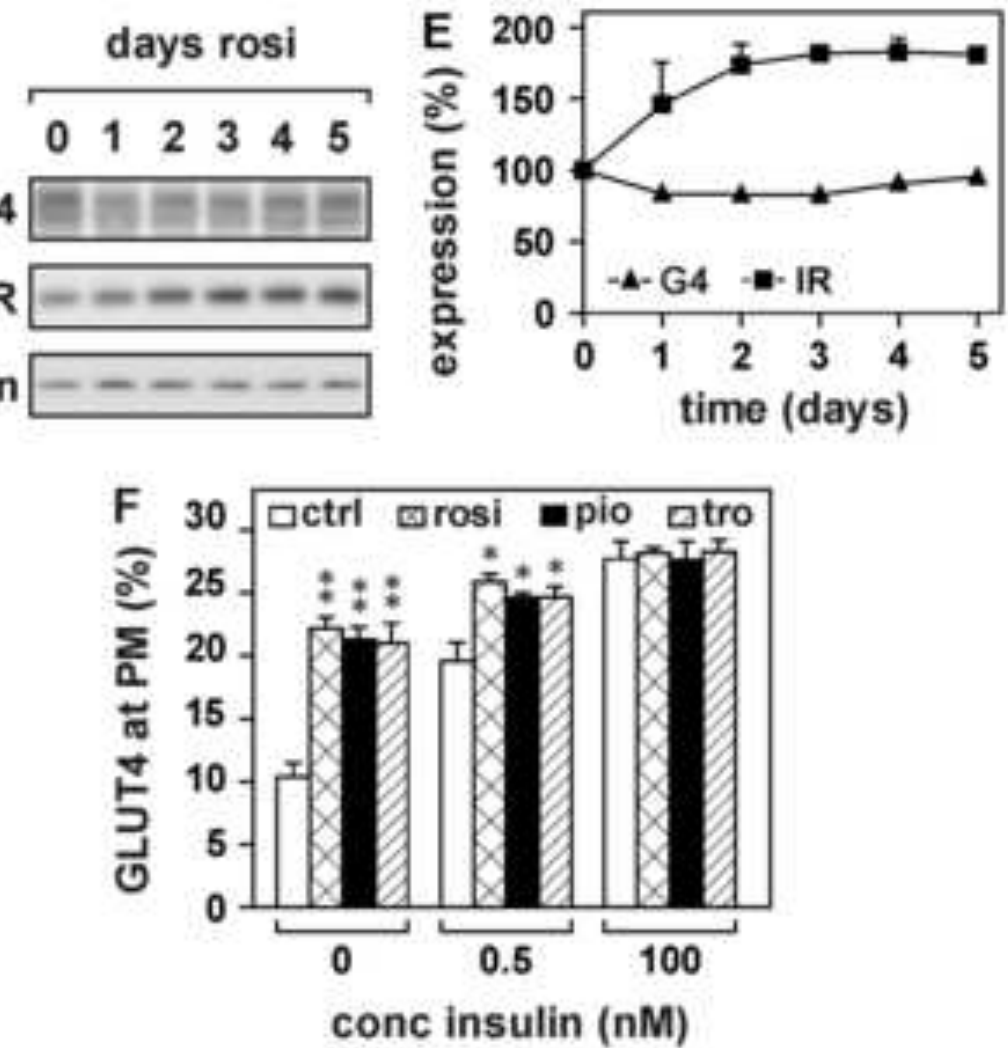

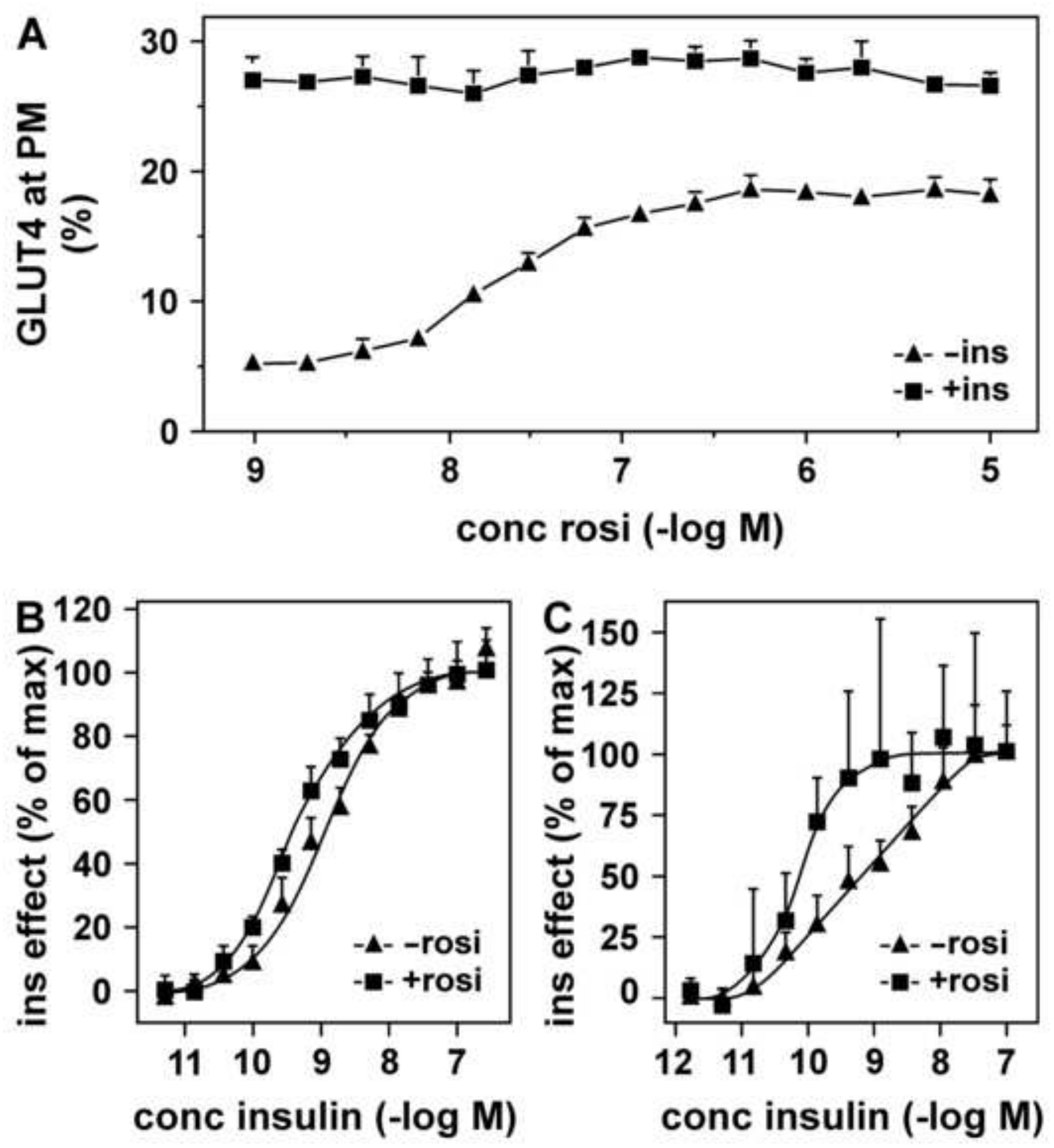

Martinez et al - Figure 5 

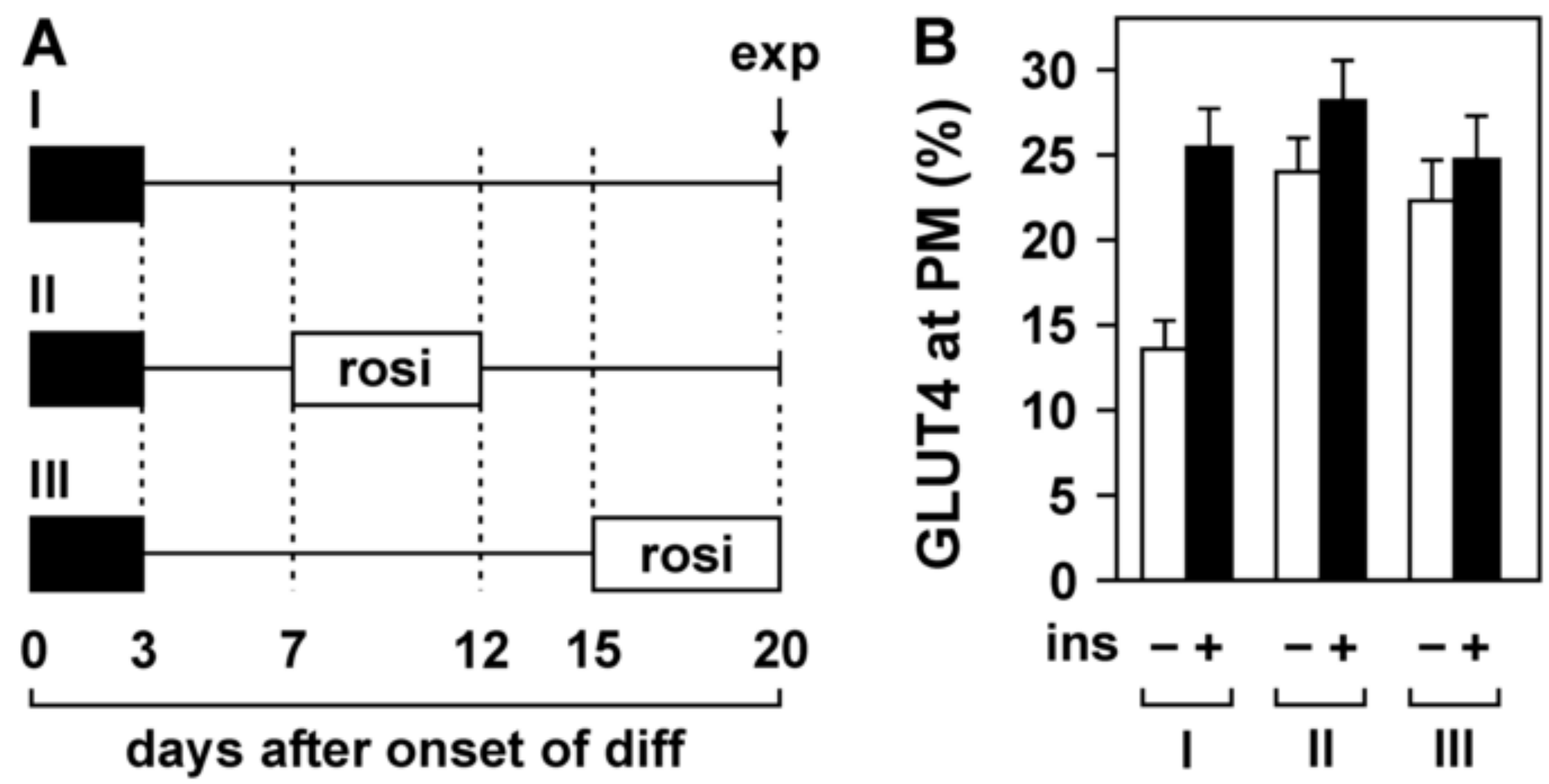

Martinez et al - Figure 6 

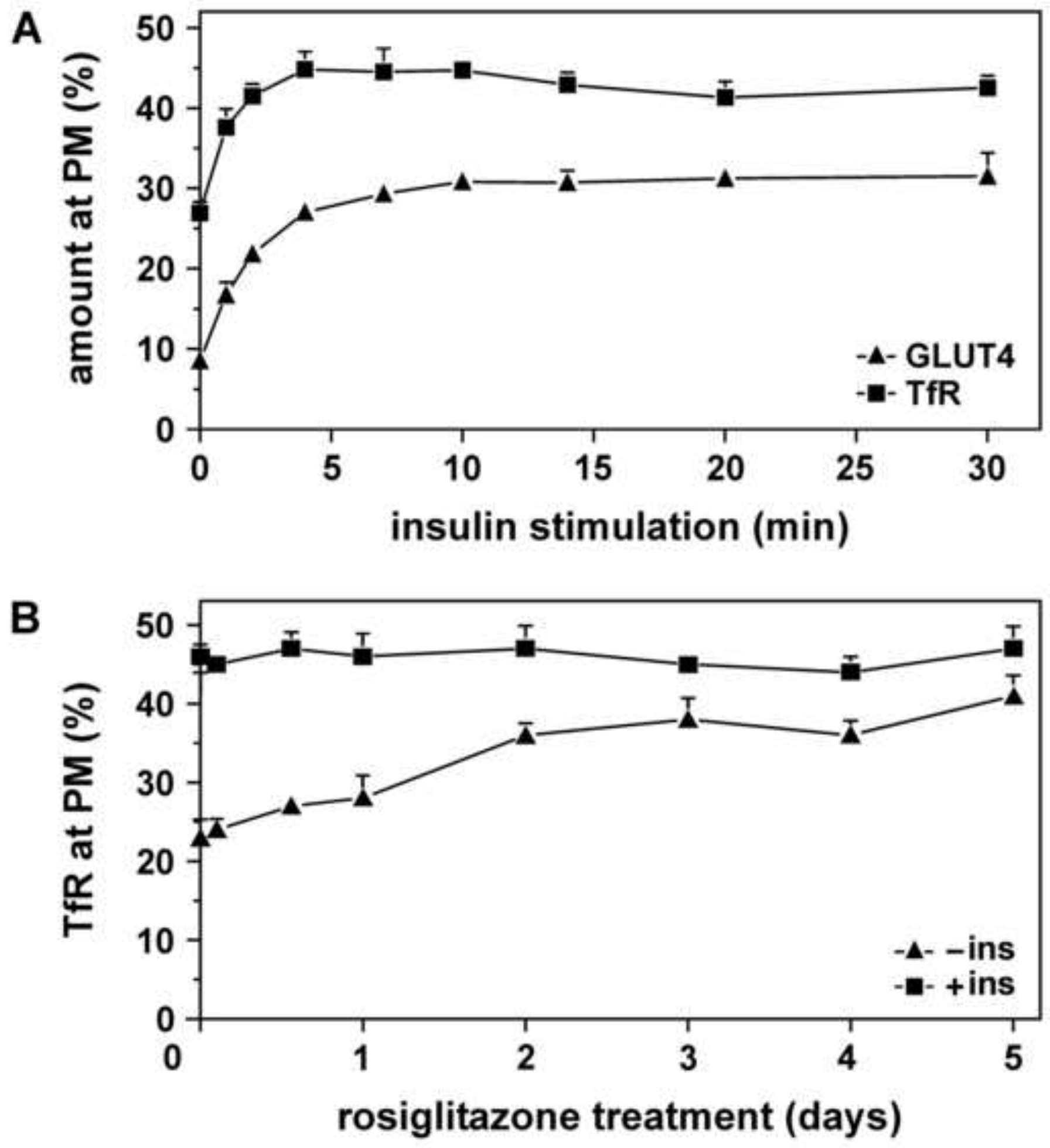

Martinez et al - Figure 7 


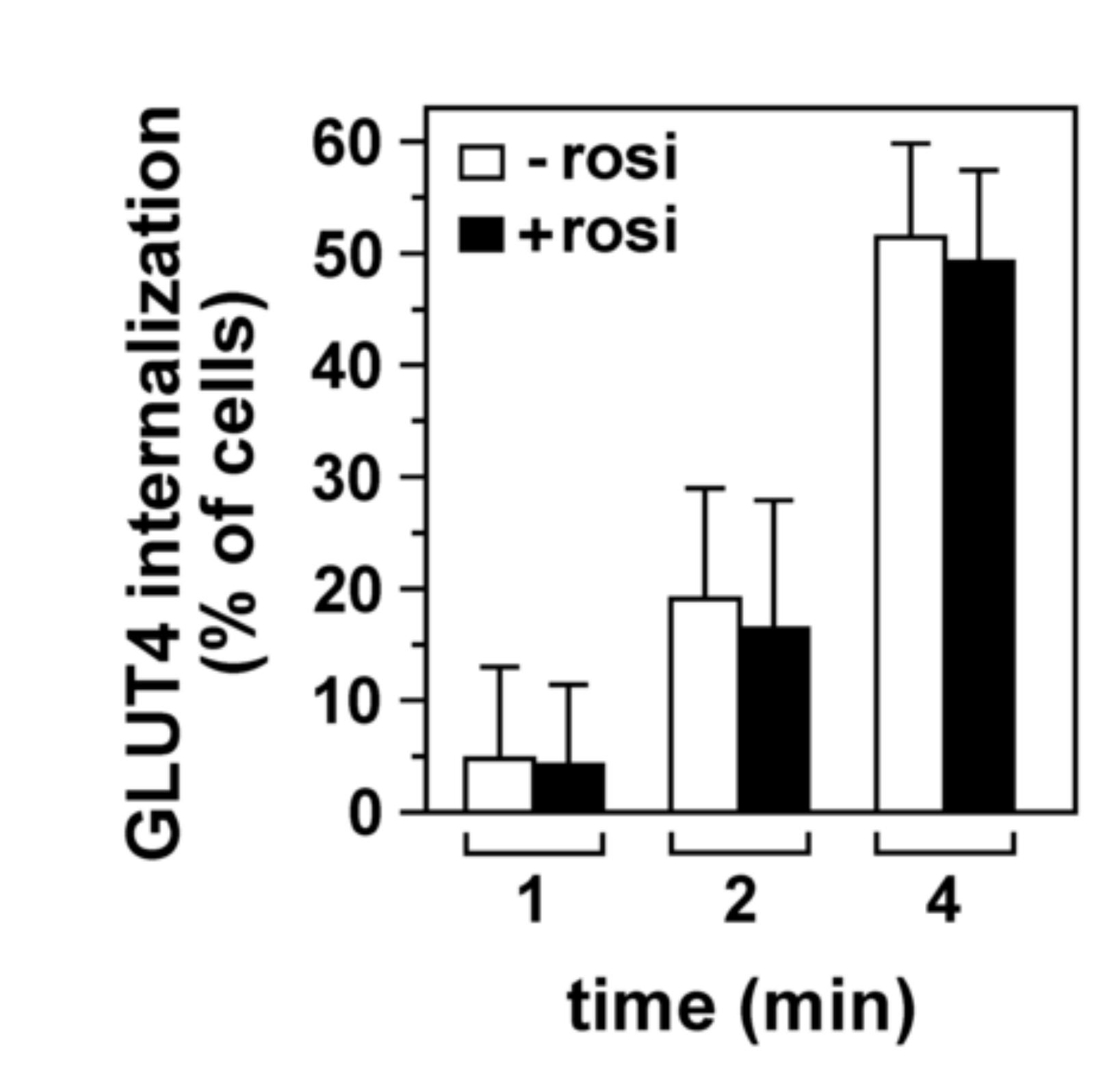

\section{Martinez et al - Figure 8}
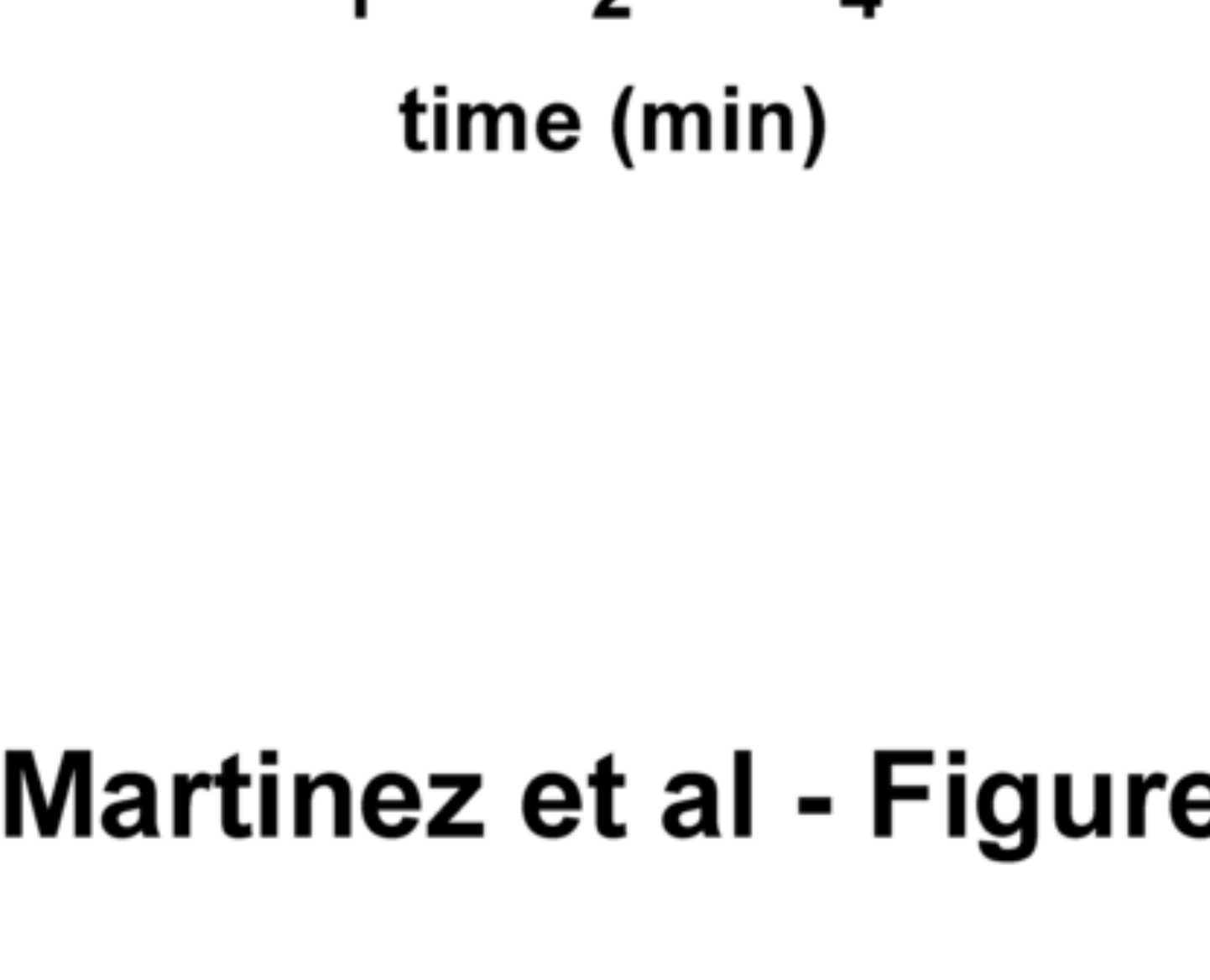

\section{8}



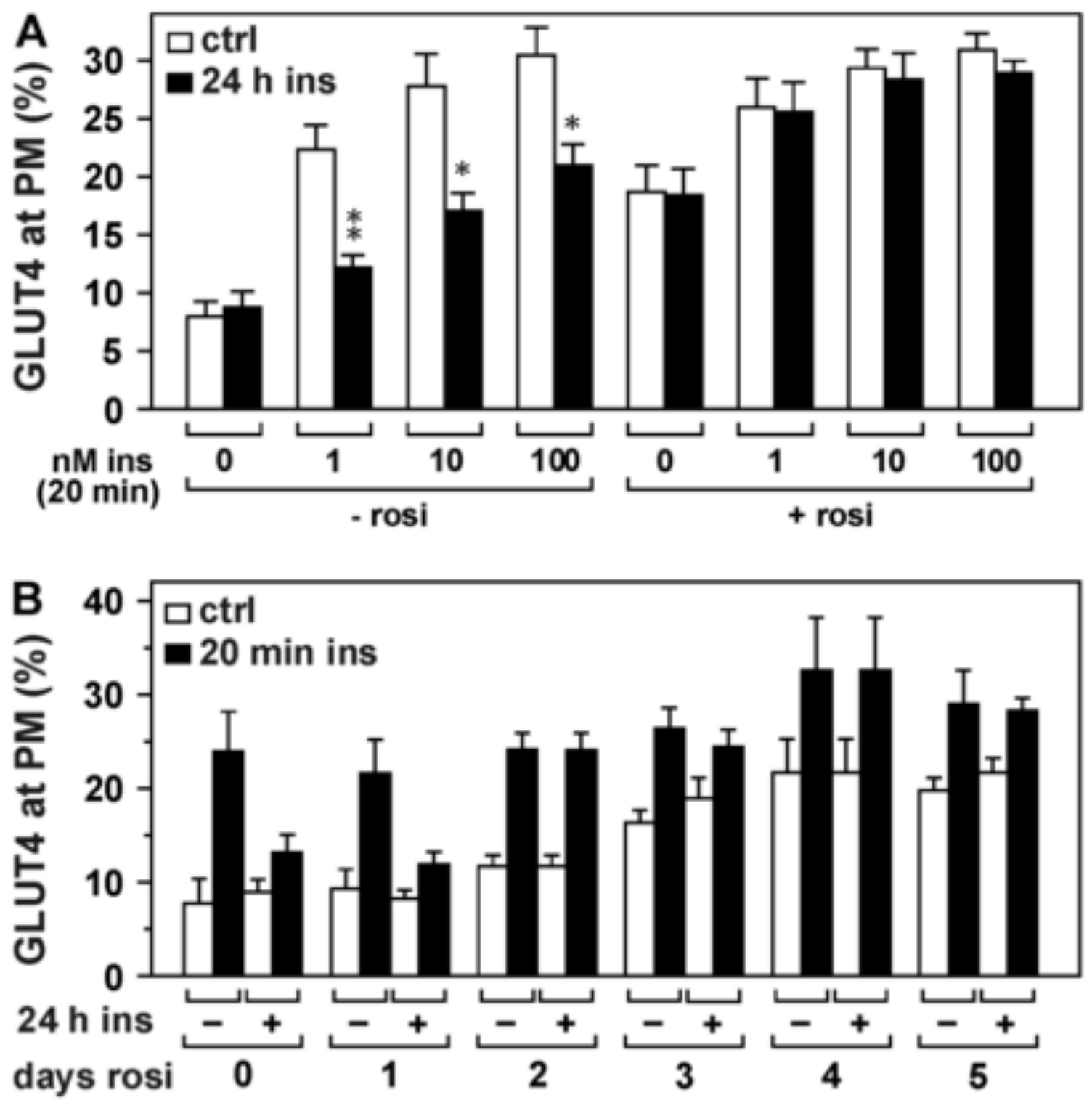

C rosi ins
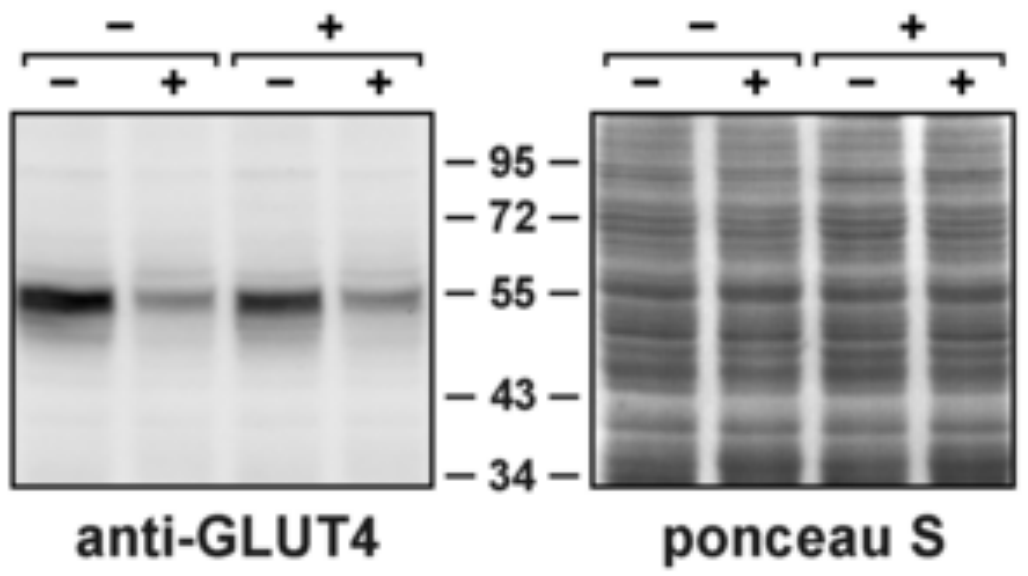

Martinez et al - Figure 9 
A

TfR

syn13

merge
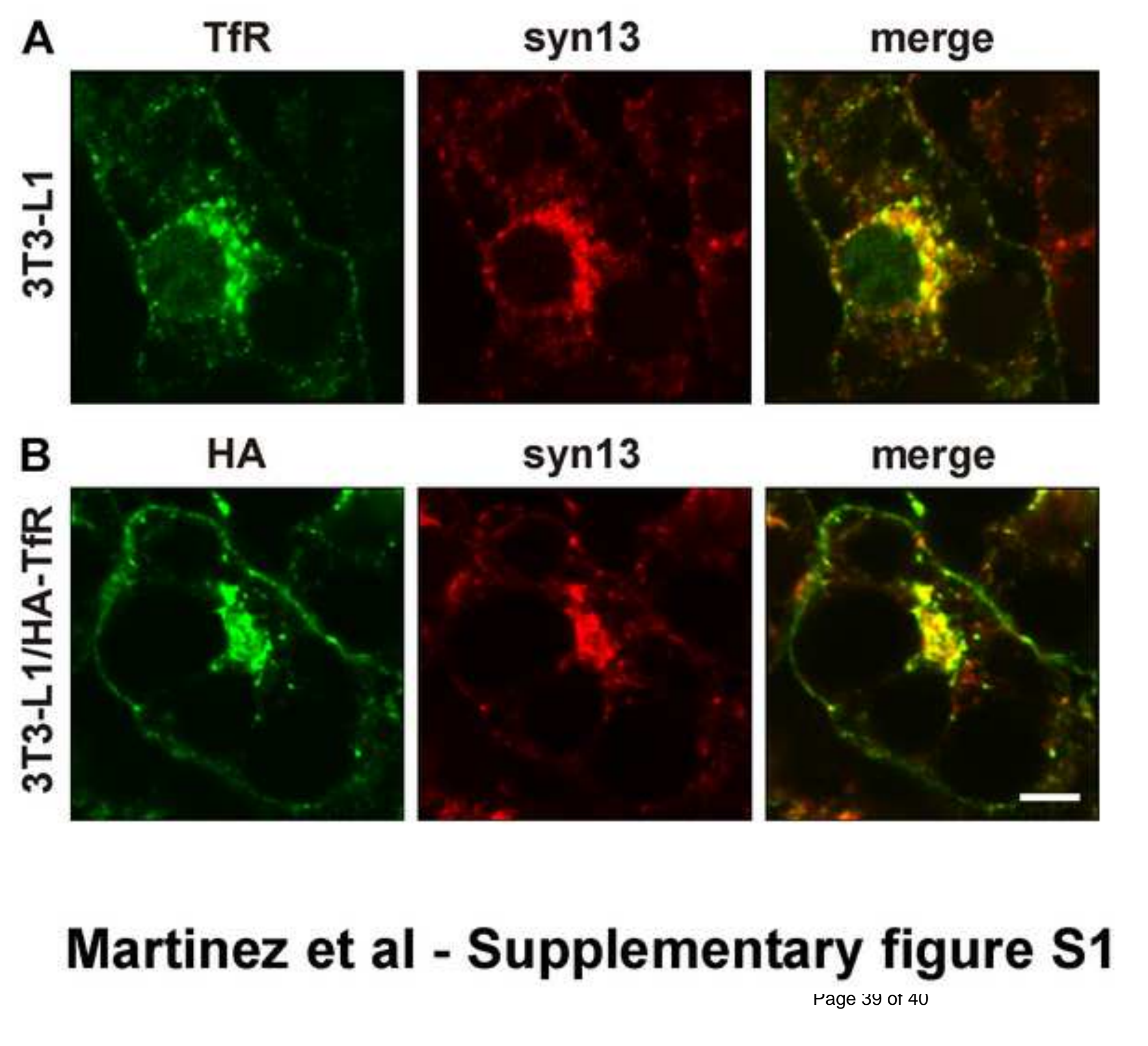

B

HA

syn13

merge
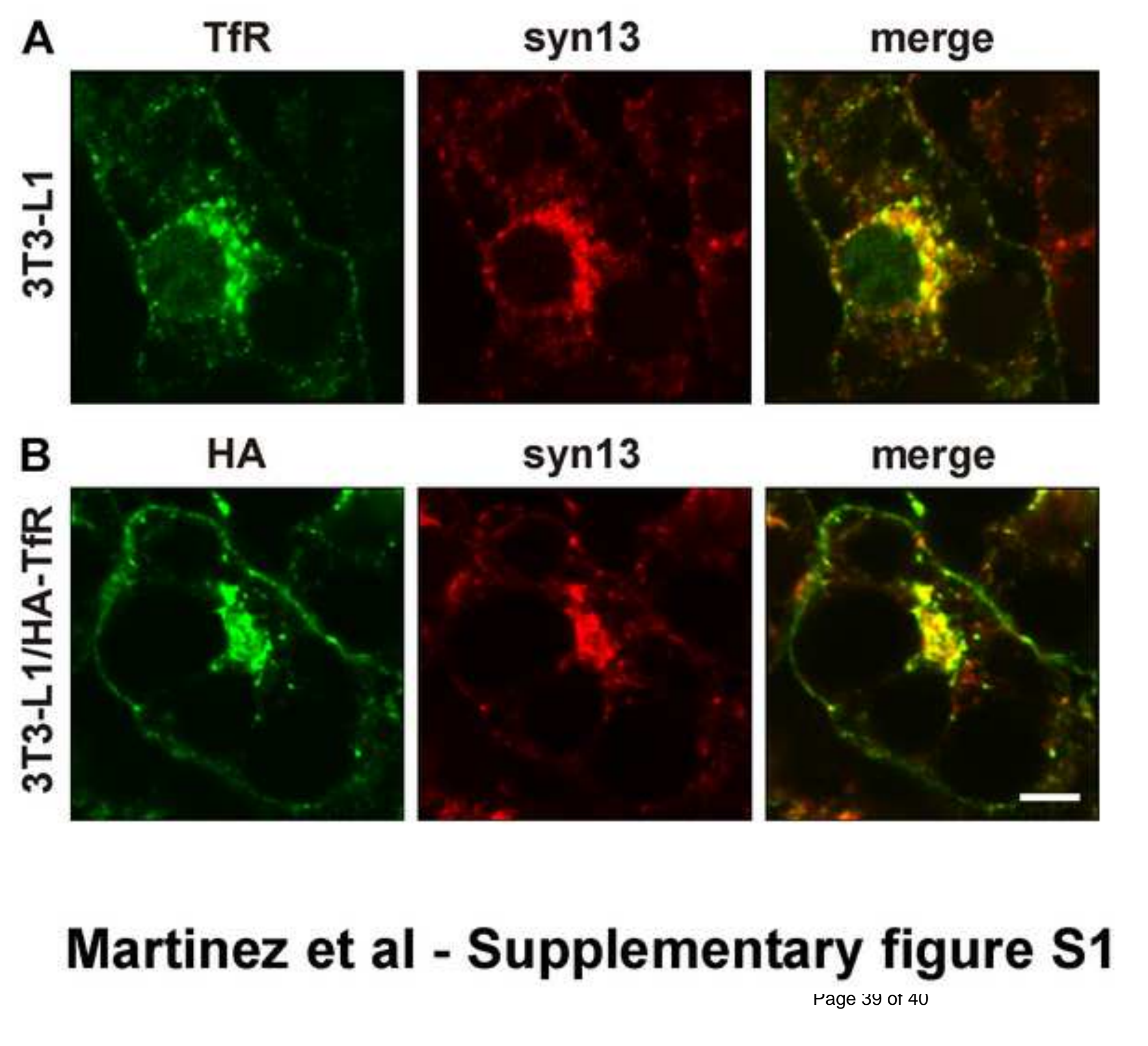

Martinez et al - Supplementary figure S1

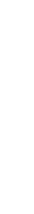
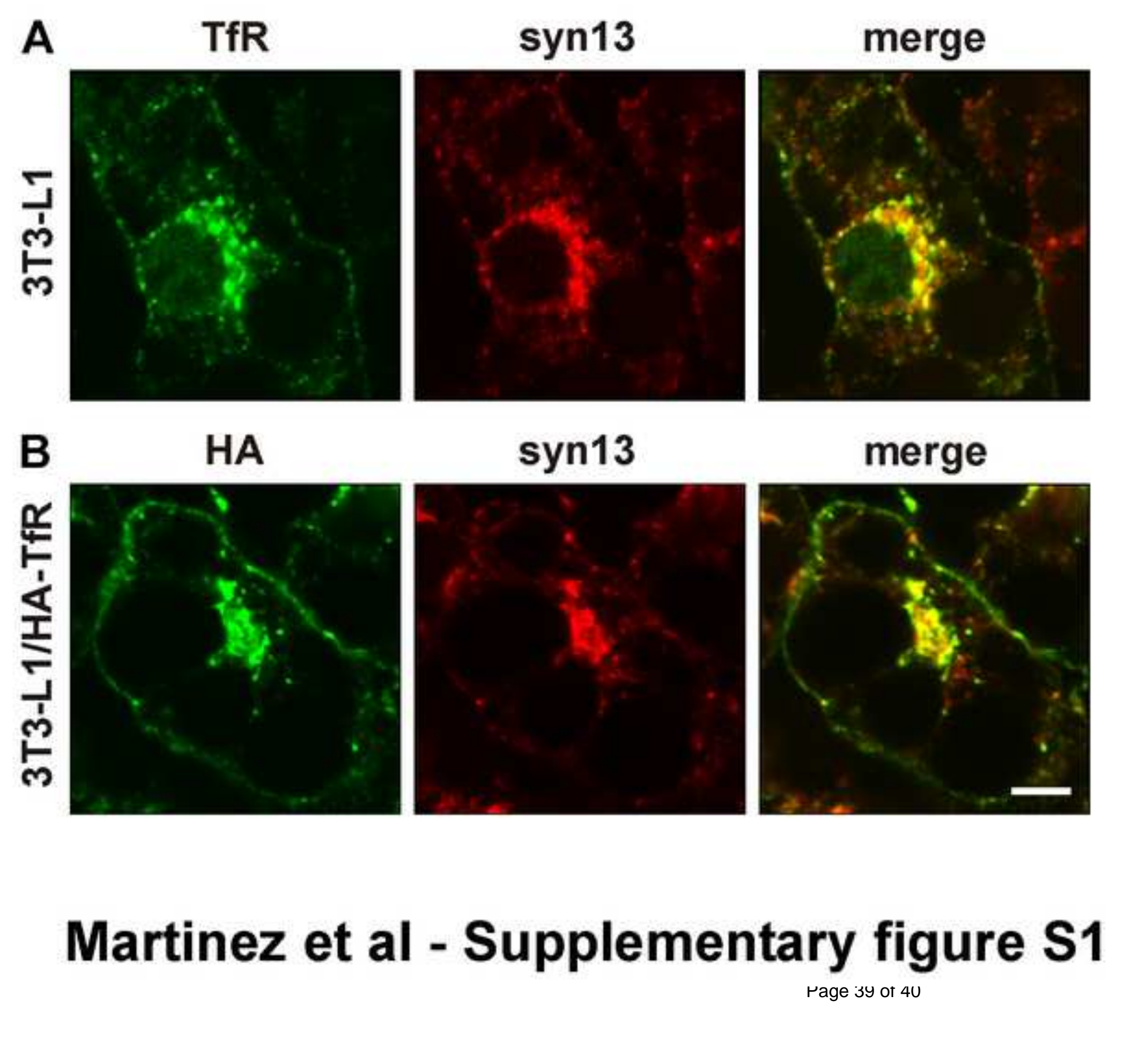

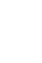

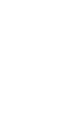




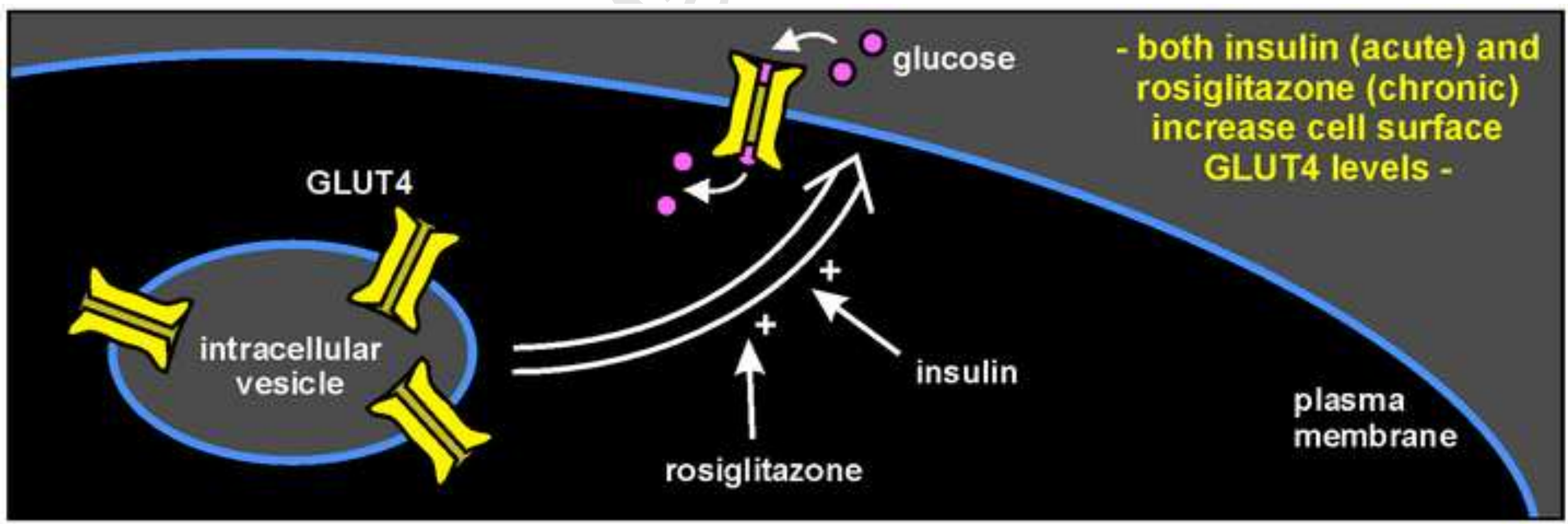

Martinez et al - graphical abstract 